\title{
Hybrid neural networks in rainfall-inundation forecasting based on a synthetic potential inundation database
}

\author{
T.-Y. Pan ${ }^{1}$, J.-S. Lai ${ }^{1,2,3}$, T.-J. Chang ${ }^{1,3,4}$, H.-K. Chang ${ }^{2,3}$, K.-C. Chang ${ }^{5}$, and Y.-C. Tan ${ }^{1,2,3}$ \\ ${ }^{1}$ Center for Weather Climate and Disaster Research, National Taiwan University, No. 1, Sec. 4, Roosevelt Rd., \\ Taipei 10617, Taiwan \\ ${ }^{2}$ Hydrotech Research Institute, National Taiwan University, Taipei 10617, Taiwan \\ ${ }^{3}$ Department of Bioenvironmental Systems Engineering, National Taiwan University, Taipei 10617, Taiwan \\ ${ }^{4}$ Ecological Engineering Research Center, National Taiwan University, Taipei 10617, Taiwan \\ ${ }^{5}$ Water Resources Agency, Ministry of Economic Affairs, 41-3 Sec. 3, Hsinyi Rd., Taipei 10651, Taiwan
}

Received: 16 August 2010 - Revised: 4 February 2011

\begin{abstract}
This study attempts to achieve real-time rainfallinundation forecasting in lowland regions, based on a synthetic potential inundation database. With the principal component analysis and a feed-forward neural network, a rainfall-inundation hybrid neural network (RiHNN) is proposed to forecast 1-h-ahead inundation depth as hydrographs at specific representative locations using spatial rainfall intensities and accumulations. A systematic procedure is presented to construct the RiHNN, which combines the merits of detailed hydraulic modeling in flood-prone lowlands via a two-dimensional overland-flow model and time-saving calculation in a real-time rainfall-inundation forecasting via ANN model. Analytical results from the RiHNNs with various principal components indicate that the RiHNNs with fewer weights can have about the same performance as a feed-forward neural network. The RiHNNs evaluated through four types of real/synthetic rainfall events also show to fit inundation-depth hydrographs well with high rainfall. Moreover, the results of real-time rainfall-inundation forecasting help the emergency manager set operational responses, which are beneficial for flood warning preparations.
\end{abstract}

\section{Introduction}

Establishing a database of potential inundation maps is a conventional non-structural measure for flood hazard mitigation in many countries. Government agencies in countries such as the USA, Japan, the UK and Taiwan have adopted flood maps as references to set up non-structural strategies in comprehensive flood management (Cabinet Office, 2003; Murphy, 2003; Lowe, 2003; Chen et al., 2006). In Taiwan, the

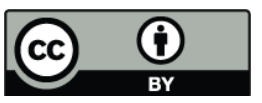

Correspondence to: T.-J. Chang (tjchang@ntu.edu.tw)
National Science and Technology Center for Disaster Reduction (NCDR) has applied the database of potential inundation for emergency managements (Yen et al., 2006). The NCDR provides the Central Emergency Operational Center, Taiwan, with an inundation map during the typhoon period. This is one of the four potential inundation databases selected and approximated to the flood extents and depths of $150 \mathrm{~mm}$, $300 \mathrm{~mm}, 450 \mathrm{~mm}$ or $600 \mathrm{~mm}$ of total rainfall in $24 \mathrm{~h}$ (Chen et al., 2006). However, these potential inundation databases as flood maps are produced by assuming that the distribution of spatial rainfall is uniform. Under the influence of spatial rainfall on flood prediction, a bias in the estimation of parameters making physical interpretation difficult may lead to overestimation of extreme flows without considering spatial variability (Arnaud et al., 2002). Spatial rainfall distribution needs to be addressed to improve the rainfall-inundation forecasting accuracy in emergency response operations.

The potential inundation database provides flood mapping information to increase awareness of those areas that could be flooded in certain conditions. It helps the emergency managers set the operational responses as non-structural measures for flood mitigation, such as allocating rescue resources, evacuating residents, or the specific transport route to shelter. A local county government in Taiwan has an emergency response time that normally takes from 2 to $3 \mathrm{~h}$ to respond to flooding (Chen et al., 2006). Various approaches have been adopted for flood inundation calculation via hydraulic or hydrological models based on data from real-time rainfall records. For modeling the inundation extent of a flood event in the lowlands, a two-dimensional (2-D) hydrodynamic model can describe hydraulic details with high accuracy in inundation depth and extent on the floodplain (Cunge et al., 1980; Wasantha Lal, 1998; Hsu et al., 2000, 2002; Bates et al., 2003; Yu and Lane, 2006; Hsieh et al., 2006; Chen et al., 2006; Guo et al., 2007). 
Artificial neural networks (ANNs) have become an attractive inductive approach in hydrological forecasting because of their flexibility and data-driven learning in building models, as well as their tolerance of inputs with error and time-saving calculation in real-time models (Thirumalaiah and Deo, 1998; Kisi and Kerem Cigizoglu, 2007). Although many studies have applied different ANNs to achieve the prediction and forecasting of various water resource aspects (Maier and Dandy, 2000; Toth et al., 2000; Bodria and Čermák, 2000; Kim and Barros, 2001; Wei et al., 2002; Pan and Wang, 2004; Kerh and Lee, 2006; Sahoo and Ray, 2006; Sahoo et al., 2006; Dawson et al., 2006; Kisi and Kerem Cigizoglu, 2007; Chau, 2007; Chen and Yu, 2007; Goswami and O'Connor, 2007; Pan et al., 2008), few investigations have utilized ANNs to achieve rainfall-inundation forecasting, which is essential to providing real-time flood warning information in emergency responses, as stated previously. An algorithm must be developed to perform realtime calculations for inundation forecasting as fast as it receives the observed rainfall records. However, a 2-D hydrodynamic model with a huge number of computational grids cannot satisfy the requirements of real-time calculations for emergency responses owing to time-consuming computations in the wide areas of the lowlands. Hence, ANNs are adopted to forecast 1-h-ahead inundation based on rainfall data at densely populated high-inundation-potential locations. To elaborate compact models, principal component analysis (PCA) is applied to extract useful information from rainfall data, and is merged with feed-forward neural networks as rainfall-inundation hybrid neural networks here. Moreover, the lack of sufficient training data is overcome by constructing a synthetic potential inundation database created by a 2-D overland-flow model as one procedure of the ANN model construction.

This work attempts to enhance the accuracy of real-time inundation forecasting for lowland regions based on a synthetic potential inundation database. The algorithm combines the merits of detailed hydraulic modeling in floodprone lowlands via the 2-D overland-flow model and timesaving calculation in real-time applications via ANN models. Accordingly, the depth and duration of flood inundation, which is crucial information for real-time emergency response operations, can be assessed. A brief description of the methodologies adopted includes hybrid neural networks and the 2-D overland-flow model in Sects. 2 and 3, respectively, which is followed by a four-step procedure of building a rainfall-inundation hybrid neural network ( $\mathrm{RiHNN}$ ) in Sect. 4. The model is applied to the 19 representative inundation locations in central western Taiwan for 1-h-ahead forecasting, and evaluated by 5 criteria in Sect. 5 . The performances of various model structures and the influence of training data are analyzed and discussed in Sect. 6. Final remarks and overall assessment of the investigation are presented in Sect. 7.

\section{Hybrid neural networks}

The ANNs are massively parallel distributed processors made up of simple processing units, which have a natural propensity for storing experiential knowledge and making it available for use. It resembles the brain in two respects: knowledge is acquired by the network from its environment through a learning process; interneuron connection strengths, known as synaptic weights, are used to store the acquired knowledge (Haykin, 1999). According to the manner of the adjustment to a synaptic weight by various data-driven learning algorithms, ANNs are classified into supervised and unsupervised neural networks. Based on the structures of the connections between neurons, ANNs are grouped into feedforward and recursive neural networks (Pan et al., 2007). As shown in Fig. 1, the ANN developed here is a multi-hiddenlayer feed-forward neural network with two different types of learning algorithms described as follows.

\subsection{BP layer}

The ANNs developed here aim to build the relation between rainfall and inundation that can substitute for traditional, time-consuming, numerical inundation models during the typhoon period, and the type of ANNs used in this study falls into the most popular class, that of the layered feed-forward network using the BP algorithm as a supervised ANN. The $\mathrm{BP}$ algorithm uses the conjugate gradient back-propagation with Fletcher-Reeves updates that can train any network as long as its weights, net input, and activation functions have derivative functions (Scales, 1985). The inputs are the observations and accumulations of the present and past-22-h rainfall of each rain gauge in the study area, and the outputs are the 1-h-ahead water depths at each representative inundation location. The formulas for the rainfall-inundation feed-forward network are shown in Eqs. (1) and (2).

$$
H_{m}(t)=f_{1}\left(\begin{array}{l}
\sum_{n}^{N} \sum_{\operatorname{lag}=0}^{\mathrm{LAG}} W_{m, n \cdot(\mathrm{lag}+1)}^{1} \cdot R_{n}(t-\mathrm{lag}) \\
+\sum_{n}^{N} \sum_{\mathrm{lag}=0}^{\mathrm{LAG}} W_{m,(\mathrm{LAG}+1) \cdot N+n \cdot(\mathrm{lag}+1)}^{1} \\
\cdot \mathrm{CR}_{n}(t-\mathrm{lag})+b_{1, m}
\end{array}\right),
$$

$m=1, \ldots, M$,

$O_{k}(t+1)=f_{2}\left(\sum_{m}^{M} W_{k, m}^{2} \cdot H_{m}(t)+b_{2, k}\right)$,

$k=1, \ldots, K$

where lag is past lag hour; $R_{n}$ ( $t$-lag) is the rainfall intensity $\left(\mathrm{mm} \mathrm{h}^{-1}\right)$ of the $n$-th rain gauge at time $t$-lag; $\mathrm{CR}_{n}(t$-lag) is the cumulative rainfall $(\mathrm{mm})$ of the $n$-th rain gauge from time $t$ to $t$-lag; $N$ is the number of rain gauges; LAG is the length of time delay (h); $W_{i, j}^{l}$ is the weight between the $i$-th neuron of the $l$-th layer and the $j$-th neuron of the $l+1$-th layer; $b_{l, j}$ 


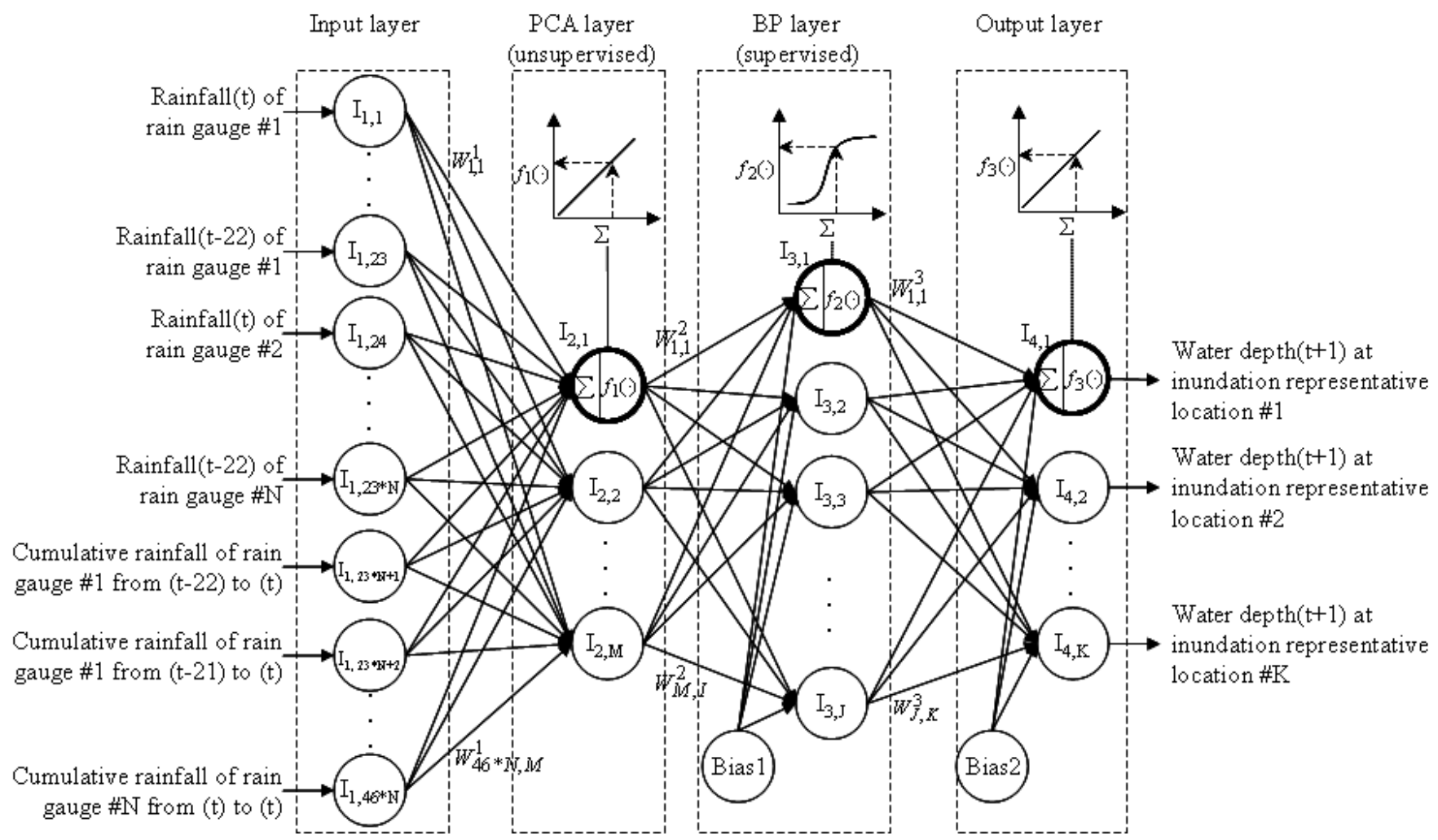

Fig. 1. Block scheme of the rainfall-inundation hybrid neural network. Each block represents a layer of neurons where $N, M, J$, and $K$ denote the number of neurons, $I$, in each layer; $N, M$, and $K$ also denote the number of rain gauges, principal components, and inundationrepresentative locations, respectively.

is the bias of the $j$-th neuron of the $l+1$-th layer; $H_{m}(t)$ is the output of the $m$-th hidden neuron at time $t ; O_{k}(t)$ is the output of the $k$-th output neuron at time $t ; f_{1}$ and $f_{2}$ are the continuous log-sigmoid function and the linear function, respectively, as the activation functions. Although the number of input neurons (dimension of the input vectors) increases with the increase of rain gauges, the components of the rainfall inputs are highly correlated (redundant).

\subsection{PCA layer}

With three effects, the principal component analysis proposes an effective procedure for reducing the dimension of the input vectors: the orthogonality of the components of the input vectors (uncorrelation between each other), the sort of the resulting orthogonal components (principal components) with the largest variation come first, and the elimination of those components that contribute the least to the variation in the input set (Jolliffe, 1986). Therefore, the correlation of the input data of the training sets can be written as follow:

Corr $=$ correlation $\left(\left[\begin{array}{c}\mathbf{R}_{i, j} \\ \mathbf{C} \mathbf{R}_{i, j}\end{array}\right]\right), i=1, \cdots,(\mathrm{LAG}+1) \cdot N$,

$j=1, \ldots$, training sets, where $\mathbf{R}$ is the matrix of rainfall intensities of training inputs; $\mathbf{C R}$ is the matrix of cumulative rainfall of training inputs; Corr is the correlation matrix of input data. Then the following equation recognized as the eigenvalue problem can be solved by linear algebra:

$\mathbf{R} \boldsymbol{q}=\lambda \boldsymbol{q}$,

where the associated values of $\boldsymbol{q}$ and $\lambda$ are called the eigenvalues and eigenvectors of the correlation matrix $\mathbf{R}$, respectively. Let the corresponding eigenvalues be arranged in decreasing order:

$\lambda_{1}>\lambda_{2}>\ldots>\lambda_{M}>\ldots>\lambda_{2 \cdot(\mathrm{LAG}+1) \cdot N}$,

where $\lambda_{1}=\lambda_{\max }, M$ is the number of principal components determined while

$\frac{\sum_{m=1}^{M} \lambda_{m}}{\sum_{m=1}^{2 \cdot(\mathrm{LAG}+1) \cdot N} \lambda_{m}} \cdot 100 \%$

$=$ percentage of explained variance $\geq$ threshold. 
Hence, the $M$ principal components can be calculated via the following equation:

$$
\begin{aligned}
P_{m}(t) & =\sum_{n}^{N} \sum_{\mathrm{lag}=0}^{\mathrm{LAG}} q_{m, n \cdot(\mathrm{lag}+1)} R_{n}(t-\mathrm{lag}) \\
& +\sum_{n}^{N} \sum_{\mathrm{lag}=0}^{\mathrm{LAG}} q_{m,(\mathrm{LAG}+1) \cdot N+n \cdot(\mathrm{lag}+1)} \mathrm{CR}_{n}(t-\mathrm{lag}), \\
m=1, \cdots, M &
\end{aligned}
$$

Furthermore, the linear combination of principal component analysis can be considered a part of ANNs as the weights of an unsupervised ANN that evolves a hybrid neural network model as shown in Fig. 1.

\subsection{Four-layer feed-forward neural network}

The hybrid neural network applied here is a four-layer feedforward neural network with $2 \cdot(\mathrm{LAG}+1) \cdot N, M, J$, and $K$ neurons in input layer, PCA layer, BP layer, and output layer where LAG, $N, M, J$, and $K$ denote, respectively, the quantities of time lags, rain gauges, principal components, neurons in BP layer, and representative inundation locations. The process can be formalized into a set of simple algebraic equations. For any hidden neuron $j$, the level of activity $I_{l+1, j}$ can be described by the following equation:

$I_{l+1, j}=f_{l}\left(\sum_{i} W_{i, j}^{l} I_{l, i}+b_{j}\right)$,

where $f_{l}$ is the activation function of the $l$-th layer as the linear, continuous log-sigmoid, and linear functions in 1 st to 3 rd layers, respectively; $I_{l, i}$ is the activity level generated from the $i$-th neurons in the $l$-th layer; $W_{i, j}^{l}$ represents the weight from the $i$-th neurons in the $l$-th layer to the $j$-th neurons in the $l+1$-th layer, and $b_{j}$ is the weighted bias, like a threshold of the opposite sign, associated with the $j$-th neurons in the $l+1$-th layer. The activation functions in PCA and output layers are linear combinations that calculate a layer's output from its net input while the hyperbolic tangent sigmoid function is selected as the activation function in the BP layer. Based on the connections with weights between neurons, each neuron computes its output response through the weighted sum of all its inputs according to its activation function and the data flows in one direction through the hybrid neural network: starting from external inputs (rainfall information) into the input layer (the predictors), that are transmitted through the PCA layer in which the rainfall information is transformed into principal components, and then passed to the BP layer for perceiving the output layer from which the external outputs (predictions of water depths at the specific representative inundation locations) are obtained.

\section{2-D overland-flow model}

With geographical information including topography, land cover, and soil type, surface overland flow processes can be appropriately described by the 2-D overland-flow model, known as the diffusive-wave model, which is based on noninertia surface flow dynamics in rural areas (Wasantha Lal, 1998; Hsu et al., 2000; Hsieh et al., 2006). Although the hydrodynamic equations, 2-D shallow water equations, describe more detailed hydraulic phenomena (Lai et al., 2005, 2010; Guo et al., 2008), the simplified form of the overlandflow model neglecting inertial terms still regarding the back water effect is physically applicable to simulate shallow water in floodplains with availability of various land uses (Vongvisessomjai et al., 1985; Bates et al., 2003). According to the performance of various numerical schemes, the alternating direction explicit (ADE) scheme shows the advantage of relatively short computational time with sufficiently high accuracy (Yen et al., 1989; Wasantha Lal, 1998). The model can attain effective prediction of flood inundation processes with respect to various land uses and spatial digital elevation model (DEM) data (Hsu et al., 2002; Yu and Lane, 2006). Therefore, the 2-D overland-flow model with the ADE scheme in the finite difference framework is adopted here.

Assuming that the inertial terms of the shallow water equations are negligible compared to gravitation and friction terms, the 2-D overland-flow model becomes:

$$
\frac{\partial \boldsymbol{Q}}{\partial t}+\frac{\partial}{\partial x} F(q)+\frac{\partial}{\partial y} G(q)=B(q),
$$

where $\boldsymbol{Q}=[h, h u, h v]^{T}$ is the vector of variables; $\boldsymbol{F}(\boldsymbol{q})=$ $\left[0, g h^{2} / 2,0\right]^{T}$ and $\boldsymbol{G}(\boldsymbol{q})=\left[0,0, g h^{2} / 2\right]^{T}$ are the flux vectors in the $\mathrm{x}$ - and y-directions, respectively; $h$ is the water depth; $u$ and $v$ are the depth-averaged velocity components in the $\mathrm{x}$ - and $\mathrm{y}$-directions, respectively; $\mathrm{g}$ is the acceleration due to gravity. The source term vector $\boldsymbol{B}(q)$ in Eq. (9) is described by the following equation:

$$
\boldsymbol{B}(\boldsymbol{q})=\left[q_{\mathrm{L}}, g h\left(S_{\mathrm{ox}}-S_{\mathrm{fx}}\right)-u q_{\mathrm{L}}, g h\left(S_{\mathrm{oy}}-S_{\mathrm{fy}}\right)-v q_{\mathrm{L}}\right]^{T},
$$

where $q_{\mathrm{L}}$ is the rainfall intensity or pumping capacity per unit area; $S_{\mathrm{ox}}=-\partial z_{\mathrm{b}} / \partial x$ and $S_{\mathrm{oy}}=-\partial z_{\mathrm{b}} / \partial y$ are the bed slopes in the $\mathrm{x}$ - and $\mathrm{y}$-directions, respectively; $z_{\mathrm{b}}$ is the bed elevation; $S_{\mathrm{fx}}$ and $S_{\mathrm{fy}}$ are the friction slopes in the x- and ydirections, respectively. The Manning formula is adopted to estimate the friction slopes, which are defined as (Chow et al., 1988):

$S_{\mathrm{fx}}=\frac{u n_{m}^{2} \sqrt{u^{2}+v^{2}}}{h^{4 / 3}}, \quad S_{\mathrm{fy}}=\frac{v n_{m}^{2} \sqrt{u^{2}+v^{2}}}{h^{4 / 3}}$,

where $n_{m}$ is Manning's roughness. Since the two-step ADE is employed, Eq. (9) is solved by the finite difference method to allow an initial condition with zero water depth and velocity. The detailed description can be found elsewhere (Chang et al., 2000; Hsu et al., 2002). 


\section{Procedures of building a rainfall-inundation hybrid neural network}

Generally, 2-D models of flood inundation are calibrated and validated based on observed inundation extent and maximum water depths through survey. However, the measurements of inundation extent and maximum water depths are limited. Most 2-D inundation models have been limited to model calibration against a single flood event, and therefore do not fully test the models' predictive power (Horritt and Bates, 2002). Although aerial imagery and satellite-derived data have been adopted to model calibration and validation, the quality of those data are still limited by the clear weather during aerial photographing. Bates and De Roo (2000) also noted the differences between the aerial imagery and satellite-derived data sets and the likely errors associated with each of these sources, subsequently leading to a significant degree of uncertainty in inundation extent observations (Romanowicz et al., 1996; Werner et al., 2005). As well as the inundation extent, the inundation-depth hydrographs are essential for calibration due to the need to assess the time and depth of the inundation peak during real-time rainfall-inundation forecasting.

Since mass observed hourly inundation-depth hydrographs are not available for the RiHNN training, the neural network is trained by a synthetic potential inundation database generated from the 2-D overland-flow model. The procedure for building the hybrid neural network has four steps as illustrated in Fig. 2.

\subsection{Step 1: validate the 2-D overland-flow model}

The ground elevation contour lines of $50 \mathrm{~m}$ and the levees are defined as the close boundaries, based on DEM and the hydraulic structures of the study area. The lateral inflows, normal to the close boundary, are set to zero since the levees are assumed to be high enough to prevent river overflow flooding. The pumping station is assumed to work normally at full capacity, and treated as a sink in numerical simulations. Manning's roughness in the model is generally estimated by applying the land use information, which is set tentatively at $0.07,0.06$ and 0.07 for commercial, residential and industrial areas, respectively (Hsu et al., 2000). The validation of the 2-D overland-flow model is determined from the simulated results and surveyed data of the inundation extent.

\subsection{Step 2: select representative inundation locations}

During the flooding emergency response operations, decision makers always focus on specific representative inundation locations where people live or work. These comprise only a part of all inundation areas shown by potential inundation maps. Hence, representative locations should be densely populated urban areas in which inundation frequently occurs. The representative locations are selected from the surveyed records, land use, satellite imagery and the potential inundation map resulting from 10-yr return-period rainfall event. These are the areas which commonly suffer apparent losses in the flood-prone lowlands in Taiwan.

\subsection{Step 3: build a synthetic potential inundation database}

The size of the training set affects the efficiency of the learning algorithm, and the variation of training significantly influences the performance of an ANN (Hagan and Menhaj, 1994; Foody et al., 1995). However, the lack of adequate data sets of observed inundation extent, the survey of maximum water depths, and inundation-depth hydrographs at the representative locations is raised for training neural networks for rainfall-inundation relation. A synthetic potential inundation database based on the calibrated 2-D overland-flow model provides adequate hourly rainfall-inundation synthetic data for training, validation and test sets.

This work employs hourly observed rainfalls of historical typhoons and storms of each rain gauge to generate four types of real/synthetic rainfall events, namely original rainfall data, original cumulative rainfalls with a design hyetograph pattern, a modified cumulative rainfall with original hyetograph pattern, and a modified cumulative rainfall with a design hyetograph pattern. The synthetic hourly rainfall data of each rain gauge is weighted to every grid as the rainfall intensity inputs for the 2-D overland-flow model. Consequently, the synthetic hourly rainfall-inundation data at each representative inundation location can be obtained from the synthetic potential inundation database generated by the $2-\mathrm{D}$ overland-flow model.

\subsection{Step 4: establish the RiHNN}

The numbers of neurons in the output and input layers of the RiHNN can be determined according to the representative inundation locations selected in step 2 and rain gauges as illustrated in Fig. 1. Based on a specific percentage of relative variance explained, the number of principal components is determined through principal component analysis of the hourly rainfall data of training set to reduce the size of the input neurons as the PCA layer shown in Fig. 2. With the validation set as a threshold for avoiding over-training, the BP algorithm is adopted to train the part of model from the PCA layer to the output layer based on the training set. The neurons in the BP layer are determined by trial and error. Consequently, the test set is employed to evaluate the performance of the RiHNN after the training process stops. 
STEP 1: Validate 2D overland-flow model.
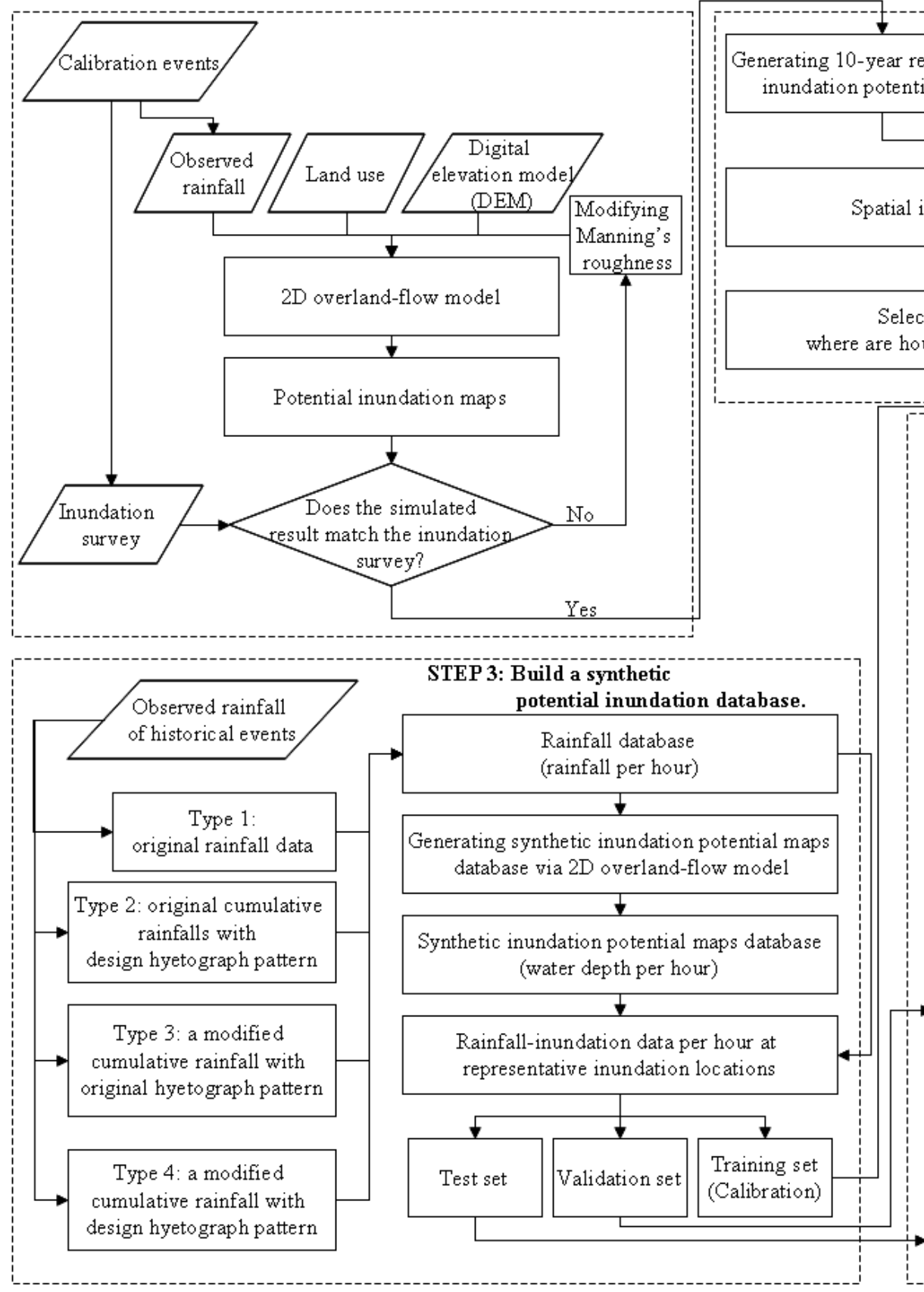

STEP 2: Select representative inundation locations.

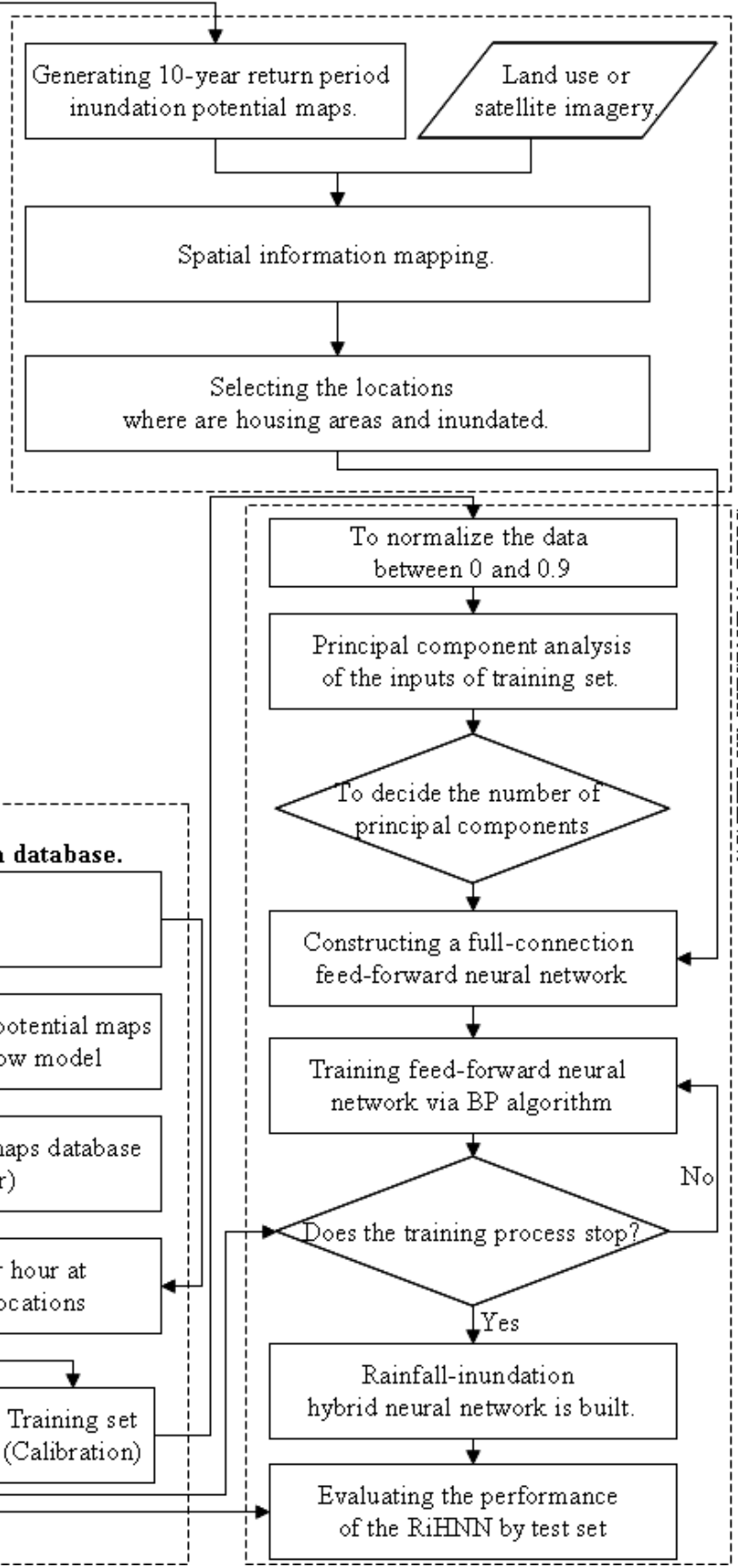

Fig. 2. The systematic procedure of building a rainfall-inundation hybrid neural network.

\section{Applications}

\subsection{Description of the study area and events}

The study area is Yunlin County, which is located in central western Taiwan, and has an area of $1291 \mathrm{~km}^{2}$ bounded by the Jhuoshuei River in the North, the Beigang River in the South, and the Central Range in the East. Yunlin county frequently suffers inundation hazards during the summer monsoon sea- son (May-October) and is subject to high mean annual precipitation $(1400 \mathrm{~mm})$. With high resolution and precision derived in 2004 from aerial photographs, the topographic data obtained from the Ministry of Interior, Taiwan, provide a spatial resolution of up to $5 \mathrm{~m}$ horizontal and $10 \mathrm{~cm}$ vertical DEM. Figure 3 shows the topography descending from east to west, illustrated by different elevation zones. The study area was divided into five control sub-areas with five automatic rain gauges using the Thiessen method: Hou-An-Liao, 


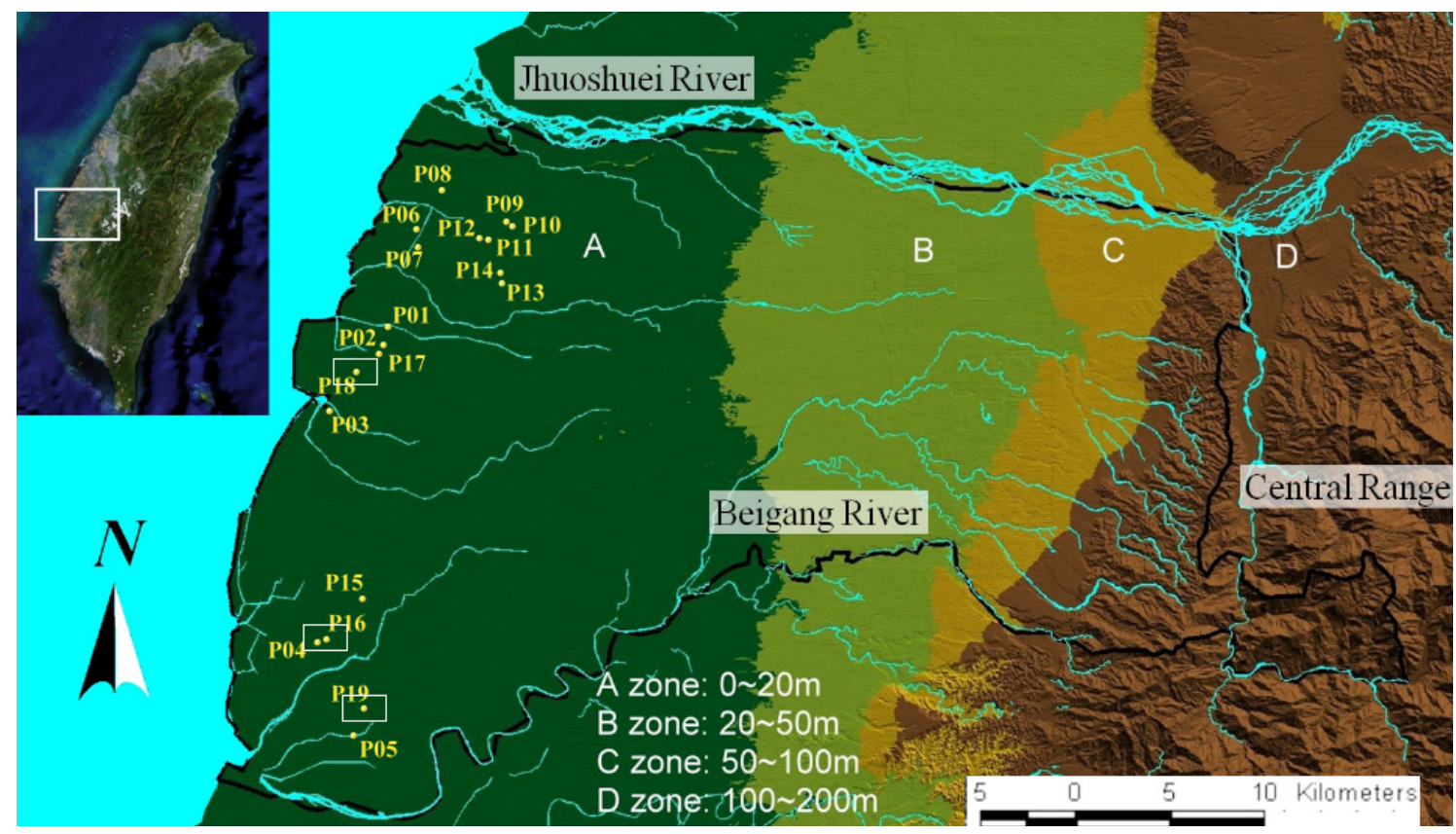

Fig. 3. The location and topography of Yunlin county, Taiwan and the 19 representative inundation locations.

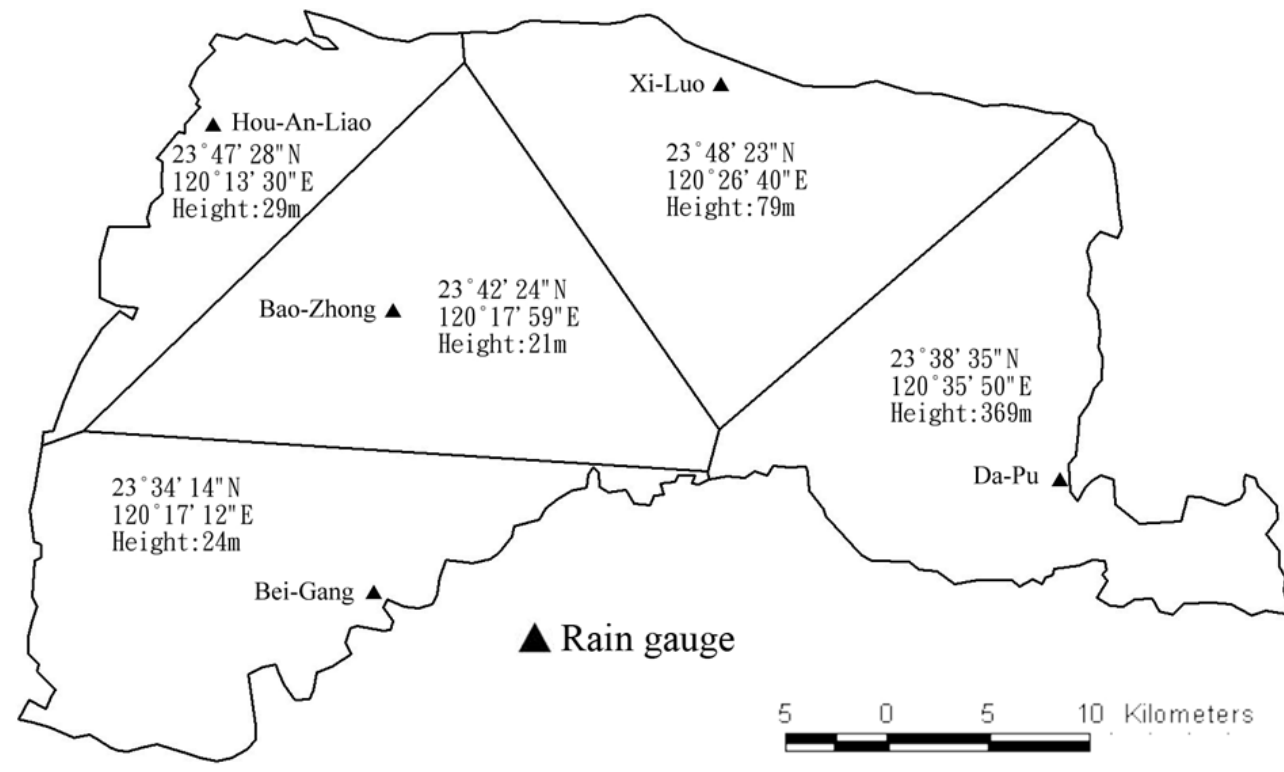

Fig. 4. The control areas with five automatic rain gauges of Yunlin using the Thiessen method.

Bao-Zhong, Bei-Gang, Xi-Luo, and Da-Pu, as illustrated in Fig. 4. The 24-h design hyetograph pattern of the all rain gauges refers to the official handbook for hydrological design (Cheng et al., 2001) as shown in Fig. 5. Frequency analysis was performed to obtain 24-h cumulative rainfall for various return periods, which are listed in Table 1. Based on the design hyetograph pattern in Fig. 5, the 24-h cumulative rainfall in Table 1 was allocated for hourly design hyetograph. As an example, Fig. 6 illustrates the potential inundation map for 10-yr return-period rainfall produced by the 2-D overlandflow model. Based on historical data from surveys of inundation extent and depth, 19 representative inundation locations were chosen as the hot spots to which early warning information should be provided for emergency response, as shown in Figs. 3 and 6. Because the representative inundation locations 16, 18 and 19 are selected for further discussion in Sect. 6.3, Fig. 3 also shows the three areas encircled by a white line. 


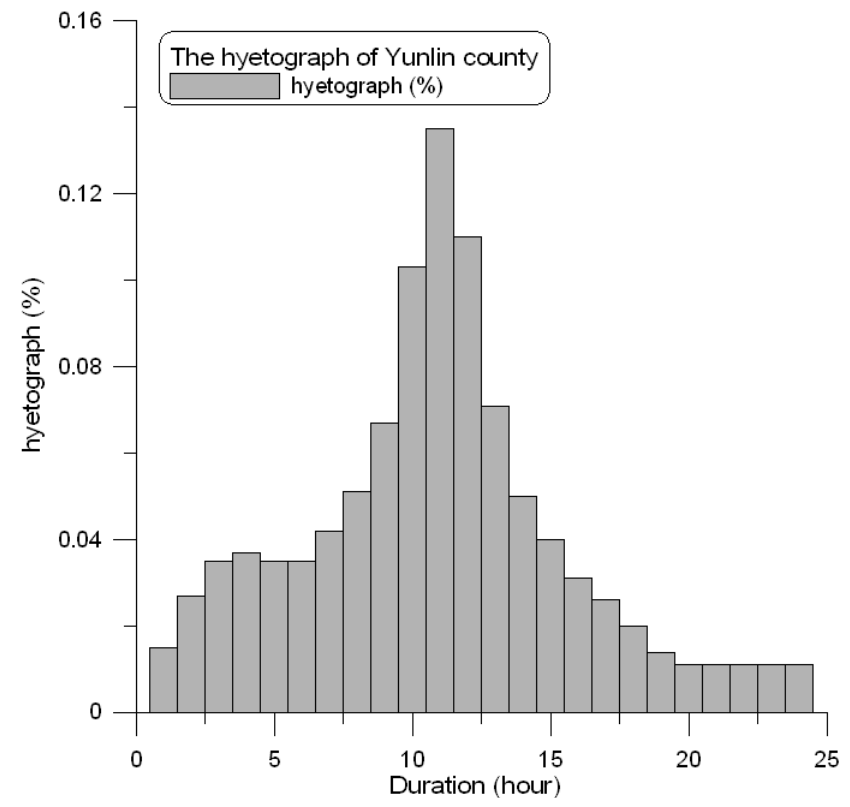

Fig. 5. The 24-h design hyetograph pattern for all rain gauges in Yunlin (Cheng et al., 2001).

Since the DEM with high resolution and precision was produced in 2004, this study has focused on the heavy rainfall events causing inundation disaster after 2004. Table 2 shows the 13 study events, comprising seven typhoons and six storms. The maximum 24-h cumulative precipitations of these five rain gauges were adopted to derive the major flooding period of each event from the original rainfall data in step 3 of Fig. 2. With an average close to $2400 \mathrm{~mm}$, the sum of 24-h cumulative precipitations of the five return periods from 20 to $200 \mathrm{yr}$ permuted in the five rain gauges fell between $2269 \mathrm{~mm}$ (Hou-An-Liao: $25 \mathrm{yr}$, Bao-Zhong: $50 \mathrm{yr}$, Bei-Gang: $200 \mathrm{yr}$, Xi-Luo: $100 \mathrm{yr}$, and Da-Pu: $20 \mathrm{yr}$ ) and $2643 \mathrm{~mm}$ (Hou-An-Liao: $50 \mathrm{yr}$, Bao-Zhong: $100 \mathrm{yr}$, BeiGang: $20 \mathrm{yr}$, Xi-Luo: $200 \mathrm{yr}$, and Da-Pu: $25 \mathrm{yr}$ ). To anticipate more severe inundations by taking frequency analysis into account, the sum of the 24 -h cumulative precipitations of five rain gauges was set to $2400 \mathrm{~mm}$ as the modified cumulative rainfall for Types 3 and 4 in step 3 of Fig. 2. Consequently, 52 synthetic inundation events, from each of the four types of rainfall, were generated and employed to construct the potential inundation database. Storm 04, Typhoons Mindulle and Sepat were selected for generate 12 synthetic inundation events as the test set according to the four types in step 3 of Fig. 2, while others were classified into the training set (36 events) and the validation set ( 4 events).
Table 1. Frequency analysis of 24-h cumulative rainfall of 5 rain gauges in Yunlin: 1 - Hou-An-Liao, 2 - Bao-Zhong, 3 - Bei-Gang, $4-\mathrm{Xi}-\mathrm{Luo}$, and 5 - Da-Pu.

\begin{tabular}{lccccc}
\hline \multirow{2}{*}{$\begin{array}{l}\text { Return period } \\
\text { (year) }\end{array}$} & \multicolumn{5}{c}{$\begin{array}{c}\text { 24-h cumulative rainfall } \\
(\mathrm{mm})\end{array}$} \\
\cline { 2 - 6 } & 1 & 2 & 3 & 4 & 5 \\
\hline 10 & 298.1 & 404.6 & 322.0 & 323.3 & 268.8 \\
20 & 316.9 & 504.3 & 370.1 & 382.2 & 324.6 \\
25 & 326.3 & 554.2 & 394.2 & 411.7 & 352.5 \\
50 & 371.9 & 668.7 & 445.0 & 478.3 & 424.3 \\
100 & 400.3 & 795.1 & 541.8 & 542.7 & 510.2 \\
200 & 424.5 & 943.0 & 620.4 & 612.6 & 609.7 \\
\hline
\end{tabular}

\subsection{Criteria}

The performances of the RiHNN were evaluated by five criteria as follows:

1. Coefficient of efficiency, CE, is defined as

$$
\mathrm{CE}=1-\frac{\sum_{n=1}^{N}\left[I_{\mathrm{obs}}(n)-I_{\mathrm{sim}}(n)\right]^{2}}{\sum_{n=1}^{N}\left[I_{\mathrm{obs}}(n)-\bar{I}_{\mathrm{obs}}\right]^{2}},
$$

where $I_{\text {sim }}(n)$ denotes the water depth (m) of the simulated inundation-depth hydrograph for time index $n$, and $I_{\text {obs }}(n)$ denotes the water depth $(\mathrm{m})$ of the observed inundation-depth hydrograph for time index $n$ during a complete event period $N$. The CE can range from $-\infty$ to 1 . An efficiency of $1(\mathrm{CE}=1)$ corresponds to a perfect match of simulated inundation-depth hydrograph to the observed data generated by the 2-D overlandflow model. An efficiency of $0(\mathrm{CE}=0)$ indicates that the model predictions are as accurate as the mean of the observed data, whereas an efficiency below zero $(-\infty<\mathrm{CE}<0)$ occurs when the observed mean is a better predictor than the model. Briefly, a CE value closer to 1 implies a better fit (Nash and Sutcliffe, 1970).

2. The error of maximum inundation depth, $\mathrm{EI}_{\mathrm{p}}(\%)$, is defined as

$\mathrm{EI}_{\mathrm{p}}=\frac{I_{\mathrm{sim}, \mathrm{p}}-I_{\mathrm{obs}, \mathrm{p}}}{I_{\mathrm{obs}, \mathrm{p}}} \cdot 100 \%$

where $I_{\mathrm{sim}, \mathrm{p}}$ denotes the maximum inundation depth (m) of the simulated hydrograph, and $I_{\mathrm{obs}, \mathrm{p}}$ denotes the maximum inundation depth (m) of the observed inundation-depth hydrograph. 


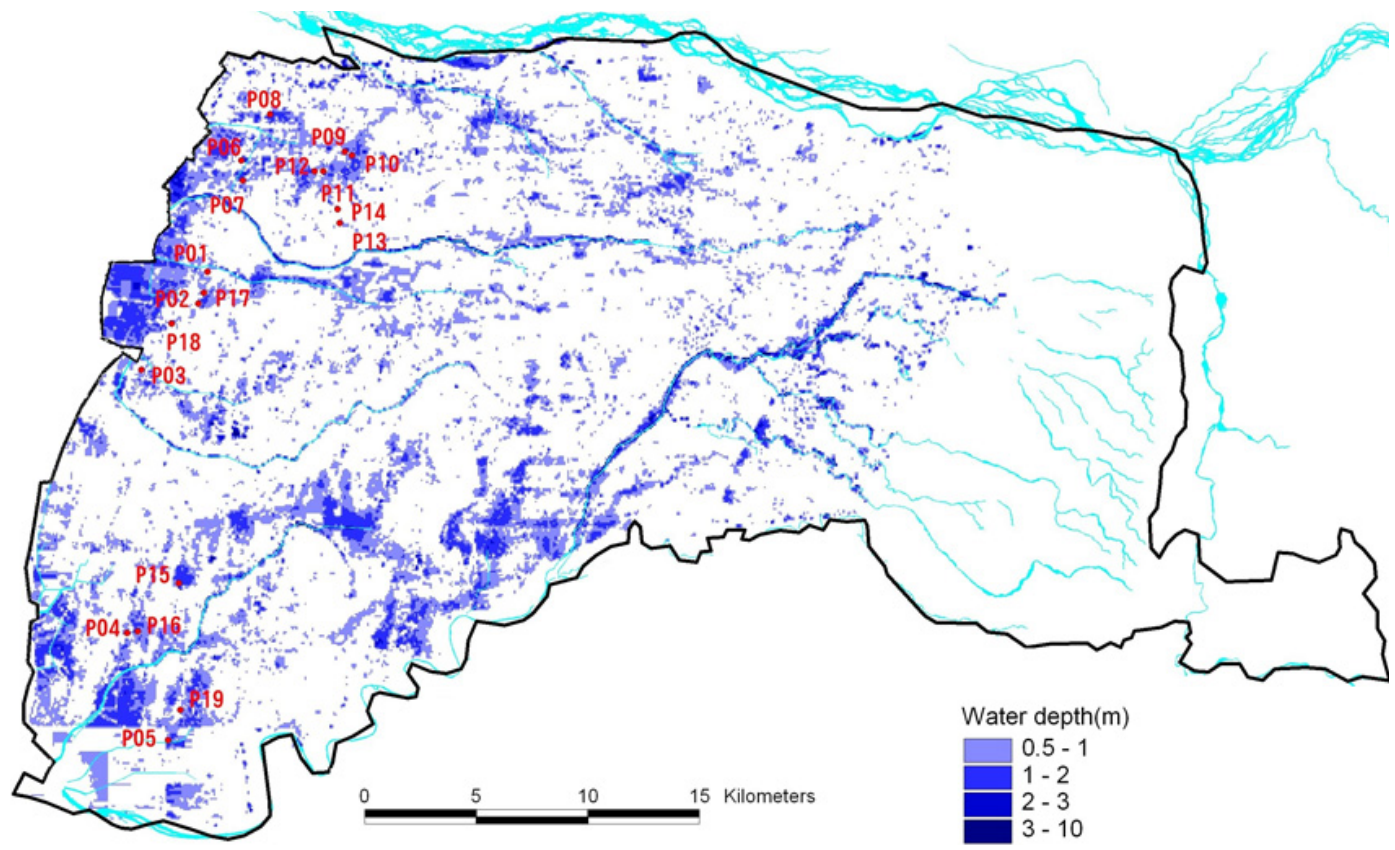

Fig. 6. Inundation map under the 24-h design rainfall event with a 10 -yr return period with 19 representative inundation locations.

Table 2. Information about the 13 events selected from Yunlin inundation history.

\begin{tabular}{|c|c|c|c|c|c|c|c|c|}
\hline \multirow[t]{2}{*}{$\begin{array}{l}\text { Event } \\
\text { No. }\end{array}$} & \multirow[t]{2}{*}{ Name } & \multirow[t]{2}{*}{ Date } & \multicolumn{5}{|c|}{$\begin{array}{l}\text { Max. 24-h cumulative precipitation } \\
\qquad\left(\mathrm{mm} 24 \mathrm{~h}^{-1}\right)\end{array}$} & \multirow[t]{2}{*}{$\begin{array}{l}\text { Sum of } 5 \text { rain gauges } \\
\qquad\left(\mathrm{mm} \mathrm{h}^{-1}\right)\end{array}$} \\
\hline & & & Bei-Gang & $\mathrm{Da}-\mathrm{Pu}$ & Bao-Zhong & Xi-Luo & Hou-An-Liao & \\
\hline 01 & Typhoon Mindulle & 2 Jul 2004 & 500.0 & 554.0 & 470.0 & 442.0 & 265.5 & 2231.5 \\
\hline 02 & Typhoon Aere & 24 Aug 2004 & 75.0 & 268.0 & 72.0 & 198.0 & 78.5 & 691.5 \\
\hline 03 & Storm 01 & 10 Sep 2004 & 80.0 & 35.0 & 44.0 & 45.0 & 53.5 & 257.5 \\
\hline 04 & Typhoon Haima & 11 Sep 2004 & 52.0 & 16.0 & 22.0 & 13.0 & 31.5 & 134.5 \\
\hline 05 & Typhoon Nanmadol & 3 Dec 2004 & 69.0 & 102.0 & 60.0 & 75.0 & 58.5 & 364.5 \\
\hline 06 & Storm 02 & 9 May 2005 & 60.0 & 70.0 & 107.0 & 153.0 & 176.5 & 566.5 \\
\hline 07 & Storm 03 & 12 May 2005 & 129.0 & 300.0 & 209.0 & 164.0 & 53.5 & 855.5 \\
\hline 08 & Storm 04 & 14 Jun 2005 & 371.0 & 155.0 & 319.0 & 241.0 & 283.0 & 1369.0 \\
\hline 09 & Typhoon Haitang & 18 Jul 2005 & 114.0 & 307.0 & 91.0 & 141.0 & 44.5 & 697.5 \\
\hline 10 & Storm 05 & 19 Jul 2005 & 169.0 & 178.0 & 97.0 & 131.0 & 77.5 & 652.5 \\
\hline 11 & Storm 06 & 20 Aug 2005 & 70.0 & 31.0 & 64.0 & 41.0 & 38.5 & 244.5 \\
\hline 12 & Typhoon Longwang & 2 Oct 2005 & 30.0 & 79.0 & 29.0 & 27.0 & 26.5 & 191.5 \\
\hline 13 & Typhoon Sepat & 18 Aug 2007 & 218.0 & 135.5 & 226.0 & 172.0 & 263.0 & 1014.5 \\
\hline
\end{tabular}

3. Root mean square error, RMSE, is defined as

$$
\mathrm{RMSE}=\sqrt{\frac{\sum_{n=1}^{N}\left[I_{\mathrm{sim}}(n)-I_{\mathrm{obs}}(n)\right]^{2}}{N}},
$$

where RMSE with same units as the quantity being estimated denotes the value by which an estimator differs from the true value of the quantity being estimated. A value of RMSE closer to 0 implies a better fit.
4. Mean absolute error, MAE, is defined as

$$
\mathrm{MAE}=\frac{\sum_{n=1}^{N}\left|I_{\mathrm{sim}}(n)-I_{\mathrm{obs}}(n)\right|}{N},
$$

where MAE denotes a quantity that is adopted to measure the closeness of forecasts or predictions to the eventual outcomes, and RMSE denotes the square root of the second moment of the error. A value of MAE closer to 0 implies a better fit. 
Table 3. The structures and performances of five RiHNNs (Models A $\sim$ E) and one feed-forward neural network (Model F).

\begin{tabular}{|c|c|c|c|c|c|c|c|c|c|c|c|c|c|c|c|c|c|c|}
\hline $\begin{array}{l}\text { 1-h ahead } \\
\text { forecasting }\end{array}$ & \multicolumn{3}{|c|}{ Model A } & & Model B & & \multicolumn{3}{|c|}{ Model C } & \multicolumn{3}{|c|}{ Model D* } & \multicolumn{3}{|c|}{ Model E } & \multicolumn{3}{|c|}{ Model F } \\
\hline $\begin{array}{l}\text { Input layer } \\
\text { (neuron no.) }\end{array}$ & \multicolumn{3}{|c|}{230} & \multicolumn{3}{|c|}{230} & \multicolumn{3}{|c|}{230} & \multicolumn{3}{|c|}{230} & \multicolumn{3}{|c|}{230} & \multicolumn{3}{|c|}{230} \\
\hline $\begin{array}{l}\text { PCA layer } \\
\text { (neuron no.) }\end{array}$ & \multicolumn{3}{|c|}{6} & & 10 & & \multicolumn{3}{|c|}{20} & \multicolumn{3}{|c|}{49} & \multicolumn{3}{|c|}{80} & \multicolumn{3}{|c|}{-} \\
\hline $\begin{array}{l}\text { Hidden layer } \\
\text { (neuron no.) }\end{array}$ & \multicolumn{3}{|c|}{132} & & 67 & & \multicolumn{3}{|c|}{50} & \multicolumn{3}{|c|}{51} & \multicolumn{3}{|c|}{100} & \multicolumn{3}{|c|}{130} \\
\hline $\begin{array}{l}\text { Output layer } \\
\text { (neuron no.) }\end{array}$ & \multicolumn{3}{|c|}{19} & & 19 & & \multicolumn{3}{|c|}{19} & \multicolumn{3}{|c|}{19} & \multicolumn{3}{|c|}{19} & \multicolumn{3}{|c|}{19} \\
\hline Weight no. & \multicolumn{3}{|c|}{4831} & & 4329 & & \multicolumn{3}{|c|}{6619} & \multicolumn{3}{|c|}{14808} & \multicolumn{3}{|c|}{28419} & \multicolumn{3}{|c|}{32519} \\
\hline $\begin{array}{l}\text { Explained } \\
\text { variance }(\%)\end{array}$ & \multicolumn{3}{|c|}{67.67} & & 75.35 & & \multicolumn{3}{|c|}{85.28} & & 95.07 & & & 99.02 & & & 100.00 & \\
\hline Status & $\mathrm{C}$ & $\mathrm{V}$ & $\mathrm{T}$ & $\mathrm{C}$ & $\mathrm{V}$ & $\mathrm{T}$ & $\mathrm{C}$ & $\mathrm{V}$ & $\mathrm{T}$ & $\mathrm{C}$ & $\mathrm{V}$ & $\mathrm{T}$ & $\mathrm{C}$ & $\mathrm{V}$ & $\mathrm{T}$ & $\mathrm{C}$ & $\mathrm{V}$ & $\mathrm{T}$ \\
\hline $\mathrm{CE}$ & 0.44 & 0.63 & 0.81 & 0.31 & 0.62 & 0.83 & 0.45 & 0.68 & 0.88 & 0.61 & 0.68 & 0.89 & 0.66 & 0.68 & 0.90 & 0.68 & 0.59 & 0.87 \\
\hline $\mathrm{EI}_{\mathrm{p}}(\%)$ & 63.14 & 38.33 & 23.77 & 26.75 & 19.43 & 1.77 & 42.16 & 11.42 & 7.20 & 10.35 & 2.51 & 4.13 & 13.24 & 2.88 & 5.56 & 17.44 & 11.29 & 5.69 \\
\hline RMSE (cm) & 12.74 & 17.81 & 14.66 & 12.46 & 14.51 & 12.77 & 10.74 & 12.29 & 11.17 & 9.87 & 11.07 & 10.40 & 8.29 & 10.61 & 9.97 & 8.29 & 11.51 & 10.69 \\
\hline MAE (cm) & 9.47 & 12.76 & 10.78 & 9.60 & 10.68 & 9.60 & 8.18 & 9.09 & 8.44 & 7.48 & 8.25 & 7.76 & 6.25 & 7.99 & 7.54 & 6.28 & 8.52 & 8.15 \\
\hline RMAE & 0.42 & 0.36 & 0.24 & 0.39 & 0.32 & 0.21 & 0.36 & 0.31 & 0.19 & 0.35 & 0.27 & 0.18 & 0.31 & 0.26 & 0.16 & 0.31 & 0.29 & 0.18 \\
\hline
\end{tabular}

Note: $\mathrm{C}$ is calibration set; $\mathrm{V}$ is validation set; $\mathrm{T}$ is test set. Model $\mathrm{D}^{*}$ is the best model.

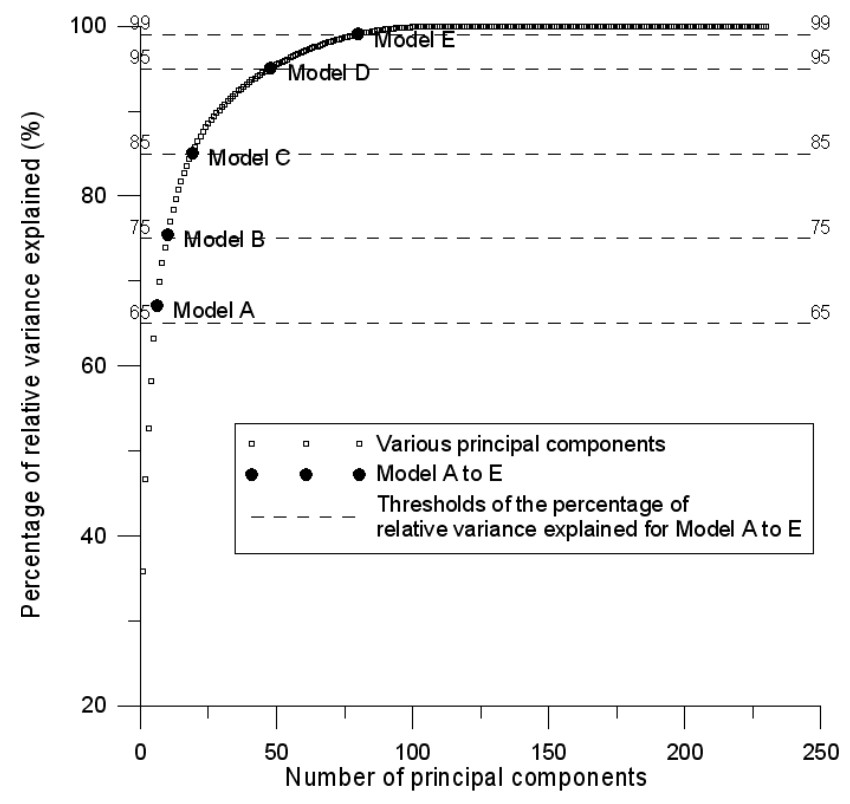

Fig. 7. Percentage of relative variance explained with different principal components.

5. Relative mean absolute error, RMAE, is defined as

$$
\mathrm{RMAE}=\frac{\mathrm{MAE}}{\bar{I}_{\mathrm{obs}}},
$$

where $\bar{I}_{\text {obs }}$ denotes the mean of water depths (m) of the observed inundation-depth hydrograph. A value of MAE closer to 0 implies a better fit.

\section{Results and discussion}

\subsection{Effect of principal component analysis}

Principal component analysis reduced the dimension of neurons in the PCA layer from 230 to less than 100, while the explained relative variance was almost $100 \%$. Figure 7 dots the five RiHNNs, plotted as Models A to E, with different numbers of principal components depending on specific thresholds of $65 \%, 75 \%, 85 \%, 95 \%$ and $99 \%$ relative variance explained, respectively, and the feed-forward neural network without the PCA layer, is denoted as Model F. The numbers of neurons in input and output layers were fixed as $46 \cdot N$ and $K$ according to the numbers of rain gauges and specific representative inundation locations, as indicated in Fig. 1. The numbers of neurons in the PCA layer were determined with the given relative variances explained as thresholds. The numbers of neurons in the hidden layer were decided by trial and error. The size of the structure of a RiHNN, including the numbers of neurons in input layer, PCA layer, hidden layer, and output layer, determined the required computer memory. A RiHNN with a smaller structure is more efficient. Table 3 lists the structure and the performance of each RiHNN.

Table 5 shows the testing performances of each RiHNN for the four types of real/synthetic rainfall events after training the RiHNNs well. Through the comparison between Tables 4 and 5 , the performances of the four-type real/synthetic rainfall events of test set were better than those of calibration set, because the events having the first three highest cumulative precipitation $\left(2231.5,1369\right.$ and $1014.5 \mathrm{~mm} 24 \mathrm{~h}^{-1}$ in Table 2) were selected as the test set. The results in Table 5 indicate that the five RiHNNs had similar performance for most criteria, except that Model A clearly had the worst 
$\mathrm{EI}_{\mathrm{p}}$ of among the five models. The seventh to tenth principal components improved the performance of RiHNN in obtaining the peak inundation, while the first six principal components contained less information about the inundation peak, as indicated by the different numbers of neurons in the PCA layers of the five RiHNNs in Table 3. Moreover, the RMSE, MAE and RMAE values reveal that the RiHNNs not only simulated events with the design hyetograph pattern better than the events without it, but also simulated events with higher rainfall better. While most RiHNNs had a CE value over 0.8 , Model D demonstrated its compact structure with the superior performances in $\mathrm{CE}$ and $\mathrm{EI}_{\mathrm{p}}$.

\subsection{Spatial rainfall-inundation forecasting}

Using the spatial precipitations of five rain gauges as inputs, the best RiHNN, Model D, was employed to forecast 1-hourahead inundation depths of the selected 19 representative inundation locations at the real-time base. Figures 8 and 9 illustrate the scatter plots of the forecasting using Model D and the synthetic inundation by a 2-D overland-flow model for the selected locations based on 12 test events. The RiHNN responded to the rainfall earlier than the 2-D overlandflow model in order to catch the inundation jumping at the beginning, as indicated by the output results at P05, P06, P08 $\sim$ P15 and P17 P19. Figure 10 shows the hydrograph of P18 as an example for discussion. This is because the durations of inundations arising from 0 to $40 \mathrm{~cm}$ in most selected locations were less than one hour, which is within the calculation time interval of RiHNN. Nevertheless, most forecasting results were close to the prefect fitting line after the initial jump in inundation, as revealed by the scatter plots. Figures 10 and 11 show the rainfall-inundation processes of Typhoon Sepat in Types 1 and 3 at representative inundation locations P16, P18 and P19. In Fig. 10, the forecasting results were compared with survey data of Typhoon Sepat (Type 1) at P18 and P19, which also validated the 2-D overland-flow model adopted here. The mapping between Figs. 4 and 6 indicates that P16 and P19 belong to the control area of the Bei-Gang rain gauge, while P18 is in the control area of the Hou-An-Liao rain gauge.

Since P16 was located in a locally-relative low place, as shown in Fig. 12, the inundation-depth hydrograph generated by the 2-D overland-flow model reflected the accumulation of the flood in both Figs. 10 and 11. Meanwhile, the forecasting water depth indicated the increasing trend based on the intensity and accumulation of precipitation in present and past $22 \mathrm{~h}$. Although a break occurred in the rainfall of the Bei-Gang rain gauge between the 13th and 17th hour, the forecasting inundation still obtained a peak following a drop at the 16th hour. According to the experience of local people in the study area, it was not easy to walk if the water was deeper than $20 \mathrm{~cm}$ during inundation. Figure 12 shows the inundation contours of $20 \mathrm{~cm}$ depth advancing with elapsed time in 2007 Typhoon Sepat. The inundation contour demon-
Table 4. Performance of RiHNNs for the four types of rainfall in calibration procedure.

\begin{tabular}{|c|c|c|c|c|c|}
\hline & $\begin{array}{l}\text { Model } \\
\text { (training) }\end{array}$ & Type 1 & Type 2 & Type 3 & Type 4 \\
\hline \multirow{5}{*}{ U } & A & 0.17 & 0.11 & 0.70 & 0.87 \\
\hline & B & -0.01 & -0.20 & 0.71 & 0.87 \\
\hline & $\mathrm{C}$ & 0.29 & -0.11 & 0.80 & 0.91 \\
\hline & $\mathrm{D}^{*}$ & 0.38 & 0.34 & 0.85 & 0.92 \\
\hline & E & 0.34 & 0.50 & 0.88 & 0.94 \\
\hline \multirow{5}{*}{$\underset{\text { â }}{\stackrel{0}{a}}$} & A & 125.26 & 7.85 & 96.01 & 13.50 \\
\hline & B & 38.77 & -14.45 & 72.14 & 7.61 \\
\hline & $\mathrm{C}$ & 84.24 & 20.47 & 48.49 & 3.16 \\
\hline & $\mathrm{D}^{*}$ & 21.30 & -4.70 & 21.82 & -0.13 \\
\hline & $\mathrm{E}$ & 17.76 & -0.57 & 28.25 & 3.39 \\
\hline \multirow{5}{*}{ 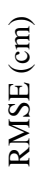 } & A & 10.74 & 7.41 & 19.94 & 14.90 \\
\hline & B & 9.71 & 7.73 & 19.42 & 13.78 \\
\hline & $\mathrm{C}$ & 9.42 & 7.01 & 15.23 & 11.92 \\
\hline & $\mathrm{D}^{*}$ & 8.58 & 6.69 & 13.90 & 10.79 \\
\hline & $\mathrm{E}$ & 7.90 & 6.13 & 10.96 & 9.10 \\
\hline \multirow{5}{*}{ 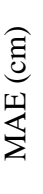 } & A & 8.27 & 5.67 & 14.27 & 10.97 \\
\hline & B & 7.48 & 5.98 & 14.65 & 10.73 \\
\hline & $\mathrm{C}$ & 7.15 & 5.35 & 11.28 & 9.30 \\
\hline & $\mathrm{D}^{*}$ & 6.71 & 5.25 & 10.13 & 8.15 \\
\hline & $\mathrm{E}$ & 6.03 & 4.69 & 8.09 & 6.89 \\
\hline \multirow{5}{*}{ 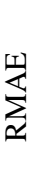 } & A & 0.68 & 0.48 & 0.31 & 0.18 \\
\hline & B & 0.58 & 0.48 & 0.31 & 0.18 \\
\hline & $\mathrm{C}$ & 0.56 & 0.47 & 0.24 & 0.16 \\
\hline & $\mathrm{D}^{*}$ & 0.54 & 0.47 & 0.22 & 0.14 \\
\hline & $\mathrm{E}$ & 0.49 & 0.44 & 0.18 & 0.12 \\
\hline
\end{tabular}

Note: Type 1 is original rainfall data.

Type 2 is design hyetographs amplified based on original cumulative rainfall. Type 3 is original hyetographs amplified based on a modified cumulative rainfall Type 4 is design hyetographs amplified based on a modified cumulative rainfall. $\mathrm{D}^{*}$ is the best model.

strates that the surrounding lowlands near village including the representative inundation location, P16, were inundated over $20 \mathrm{~cm}$ following the 11th hour owing to overland flow. P16 suffered inundation about one hour earlier than the village area. Thus, residents in the village had $2 \mathrm{~h}$ to make emergency responses for evacuation or transportation to shelter, based on the 1-h-ahead forecasting by RiHNN.

Around P18 located south of the village, the shallow flow was driven through by the topography effect from the east to the west, as shown in Fig. 13. Based on the 2-D overlandflow model, the peak rainfall at the Hou-An-Liao rain gauge induced rising inundation at the 11th hour, and was released slowly from east to west, while the second peak rainfall at 18th hour only caused the water depth to rise slightly in Fig. 10. Due to the magnification of precipitation of Typhoon Sepat in Fig. 11, the risen inundation induced by the peak rainfall at the eighth hour was higher than that in Fig. 10, and the bigger rainfall later caused the second inundation peak of 
Table 5. Performance of RiHNNs for the four types of rainfall in test procedure.

\begin{tabular}{|c|c|c|c|c|c|}
\hline & $\begin{array}{l}\text { Model } \\
\text { (test) }\end{array}$ & Type 1 & Type 2 & Type 3 & Type 4 \\
\hline \multirow{5}{*}{ Uు } & A & 0.70 & 0.76 & 0.85 & 0.91 \\
\hline & B & 0.75 & 0.84 & 0.81 & 0.91 \\
\hline & $\mathrm{C}$ & 0.82 & 0.88 & 0.89 & 0.94 \\
\hline & $\mathrm{D}^{*}$ & 0.85 & 0.88 & 0.90 & 0.94 \\
\hline & $\mathrm{E}$ & 0.86 & 0.87 & 0.91 & 0.94 \\
\hline \multirow{5}{*}{$\underbrace{20}_{0}$} & A & 44.22 & 11.46 & 26.40 & 13.00 \\
\hline & B & 6.01 & -1.84 & 1.95 & 0.95 \\
\hline & $\mathrm{C}$ & 16.51 & 5.57 & 6.55 & 0.17 \\
\hline & $\mathrm{D}^{*}$ & 11.31 & 3.46 & 2.79 & -1.05 \\
\hline & $\mathrm{E}$ & 8.95 & 0.48 & 10.08 & 2.74 \\
\hline \multirow{5}{*}{ 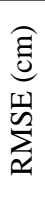 } & A & 15.41 & 13.90 & 16.71 & 12.60 \\
\hline & B & 13.67 & 10.72 & 15.31 & 11.38 \\
\hline & $\mathrm{C}$ & 12.44 & 9.46 & 13.11 & 9.68 \\
\hline & $\mathrm{D}^{*}$ & 11.03 & 9.15 & 12.49 & 8.94 \\
\hline & $\mathrm{E}$ & 10.37 & 8.70 & 12.13 & 8.69 \\
\hline \multirow{5}{*}{ 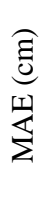 } & A & 10.94 & 10.53 & 11.93 & 9.71 \\
\hline & B & 9.97 & 8.30 & 11.23 & 8.91 \\
\hline & $\mathrm{C}$ & 9.14 & 7.39 & 9.70 & 7.52 \\
\hline & $\mathrm{D}^{*}$ & 8.16 & 7.02 & 9.15 & 6.71 \\
\hline & $\mathrm{E}$ & 7.76 & 6.70 & 8.90 & 6.78 \\
\hline \multirow{5}{*}{$\sum_{\Delta}^{\infty}$} & A & 0.34 & 0.27 & 0.21 & 0.14 \\
\hline & B & 0.31 & 0.22 & 0.20 & 0.13 \\
\hline & $\mathrm{C}$ & 0.29 & 0.20 & 0.17 & 0.11 \\
\hline & $\mathrm{D}^{*}$ & 0.26 & 0.19 & 0.16 & 0.10 \\
\hline & $\mathrm{E}$ & 0.23 & 0.18 & 0.16 & 0.10 \\
\hline
\end{tabular}

P18 in Fig. 11. The differences in the inundation-depth hydrographs generated by the 2-D overland-flow model demonstrate that different cumulative rainfall would induce different hydrograph patterns, even when the hyetograph patterns were the same. Although the forecasting at P18 only reflected the changes of cumulative rainfall between Figs. 10 and 11 without modification of hydrograph patterns, the rising segment of inundation was still close to the inundation generated by the 2-D overland-flow model, especially in high-cumulative-rainfall events. The inundation contour in Fig. 13 also indicates that inundation occurred P18, suffering one hour earlier than that within the village area northwest of P18. Hence, residents would have at least $2 \mathrm{~h}$ to make emergency responses.

The inundation of P19 occurred after water filled up the lower areas nearby, according to Fig. 14. The advance of $20 \mathrm{~cm}$-deep contour lines demonstrates the rising of the inundation depth from lower to higher areas. Hence, the different cumulative rainfall with the same hyetograph pattern between Figs. 10 (Type 1) and 11 (Type 3) induced not only changes of peak inundation, but also differences in the hy- drographs of inundation depth. The forecasting performance of P19 indicated in Figs. 10 and 11 confirms that the forecasting is more accurate for high rainfall than that for slight inundation, as discussed in Sect. 6.2. The RiHNN matched not only the trend but also the peaking time of inundation for Type 3 in Fig. 11, although the maximum inundation depth was poor for Type 1 in Fig. 10. Moreover, P19 suffered inundation (see Fig. 14) about $2 \mathrm{~h}$ earlier than the village area during Typhoon Sepat. The 1-h-ahead forecasting provided by the RiHNN would give the residents about $3 \mathrm{~h}$ for emergency responses.

From the above analyses, the RiHNN predicted 1-h-ahead inundation depth acceptably at the representative inundation locations through spatial rainfall information according to Table 5 and Figs. 10 and 11. Accordingly, it may normally take from 2 to $3 \mathrm{~h}$ for emergency managers of a local county government in Taiwan to set the operational responses, as mentioned previously. Based on the event study for the Typhoon Sepat, the elapsed time of advancing $20 \mathrm{~cm}$-deep inundation contour lines from the representative inundation locations (P16, P18 and P19) to the protected villages are about 2 to $3 \mathrm{~h}$, which concludes that site selection of the distributed representative inundation locations would have been beneficial for real-time flood warning preparations.

\section{Conclusions}

This study presents a systematic flowchart for developing a rainfall-inundation hybrid neural network (RiHNN) that combines principal component analysis with a feed-forward network to forecast the real-time 1-hour-ahead water depth of inundation at distributed representative inundation locations based on the spatial intensities and accumulations of observed rainfall. For lack of surveyed inundation-depth hydrographs in artificial neural network (ANN) training, the 2-D overland-flow model was adopted to generate mass potential inundation maps based on real/synthetic rainfall events. Although building a synthetic potential inundation database is time-consuming, a well-trained RiHNN that stores the characteristics of inundation flows can respond to the specific representative inundation locations in a real-time calculation during flood disasters. The proposed RiHNN combines the merits of detailed hydraulics in flood-prone lowlands via the 2-D overland-flow model and time-saving calculation via ANN model.

Since principal component analysis (PCA) is embedded in the PCA layer, the RiHNNs with various principal components are compared with a feed-forward neural network. Analytical results indicate that RiHNNs obtain the same performance as a feed-forward neural network with fewer weights. Hence, this study proposes an efficient and compact RiHNN with a 230-49-51-19 structure (see Table 3) to forecast the inundations of 19 representative inundation locations based on the rainfall records of 5 rain gauges. Moreover, 

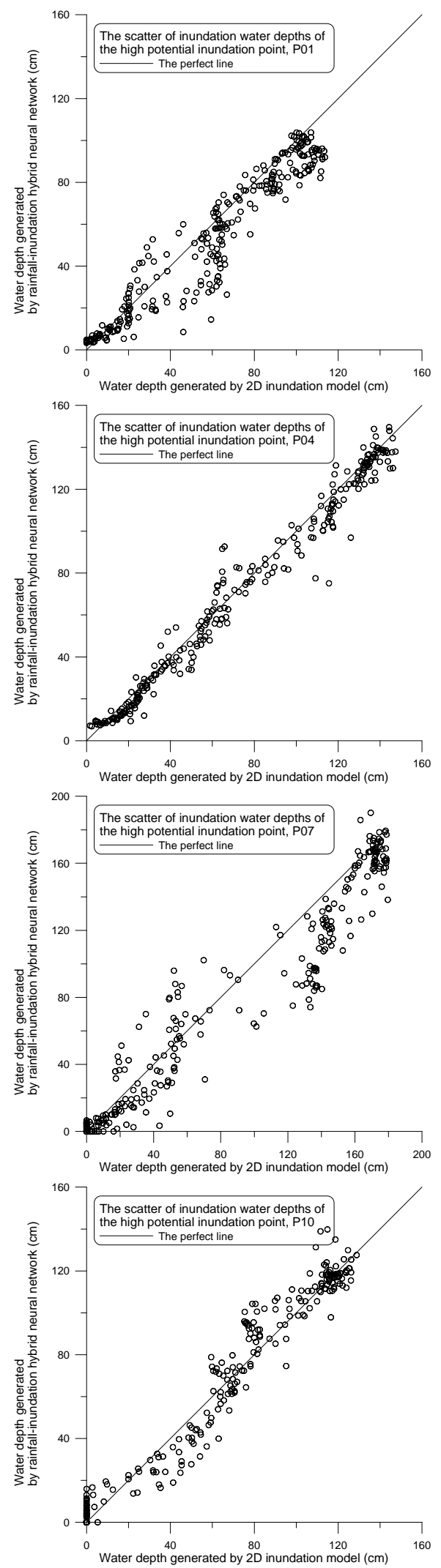
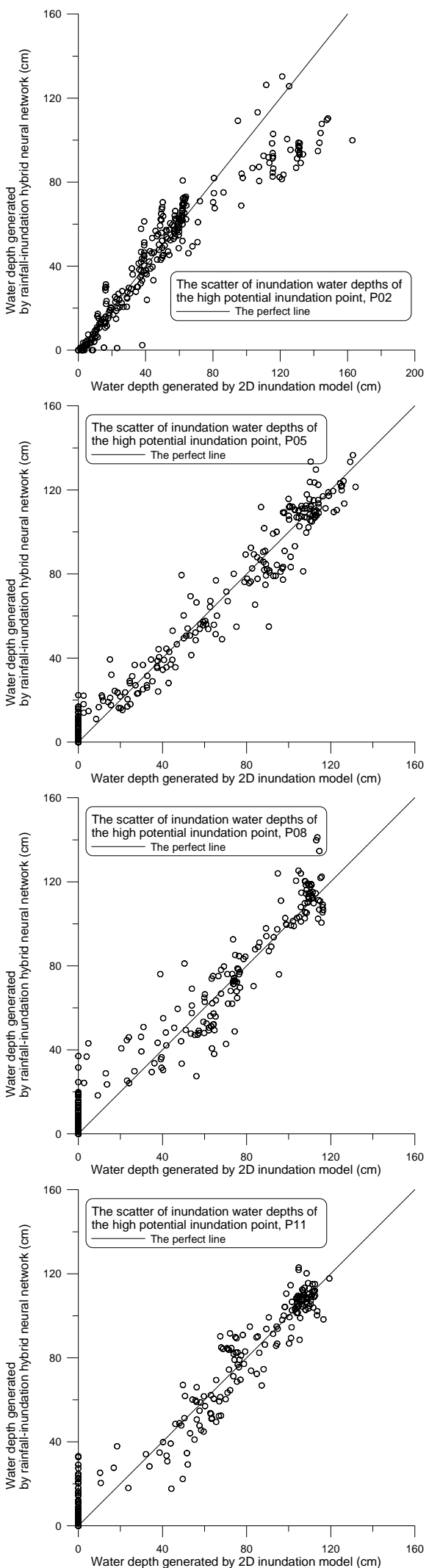
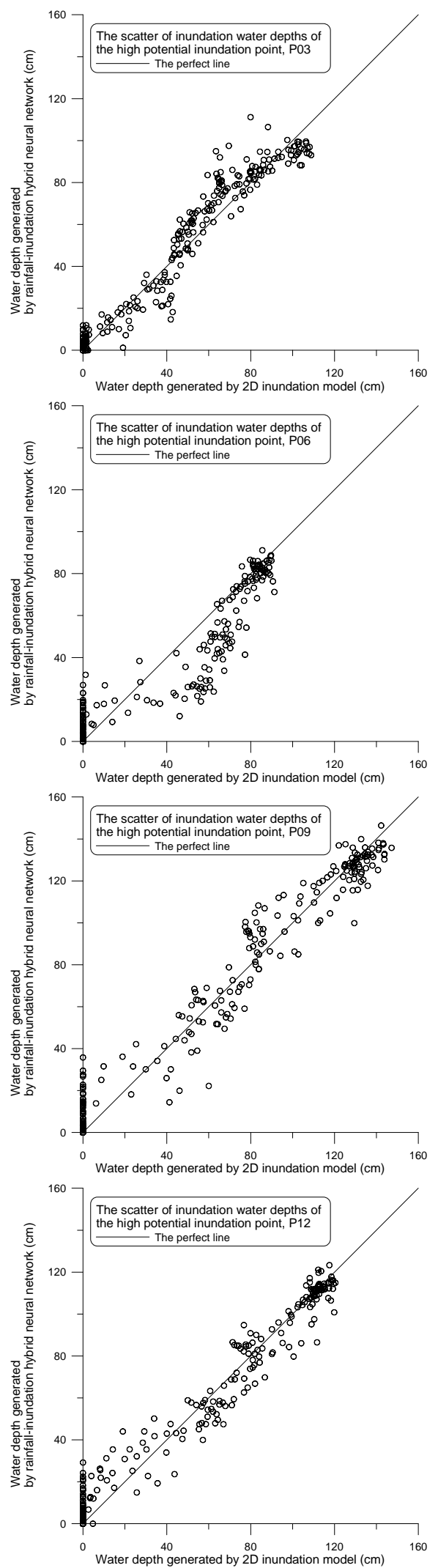

Fig. 8. The scatter plots of the forecast by RiHNN (Model D) and the synthetic inundation by 2-D overland-flow model for the P01 P12 representative inundation locations. 

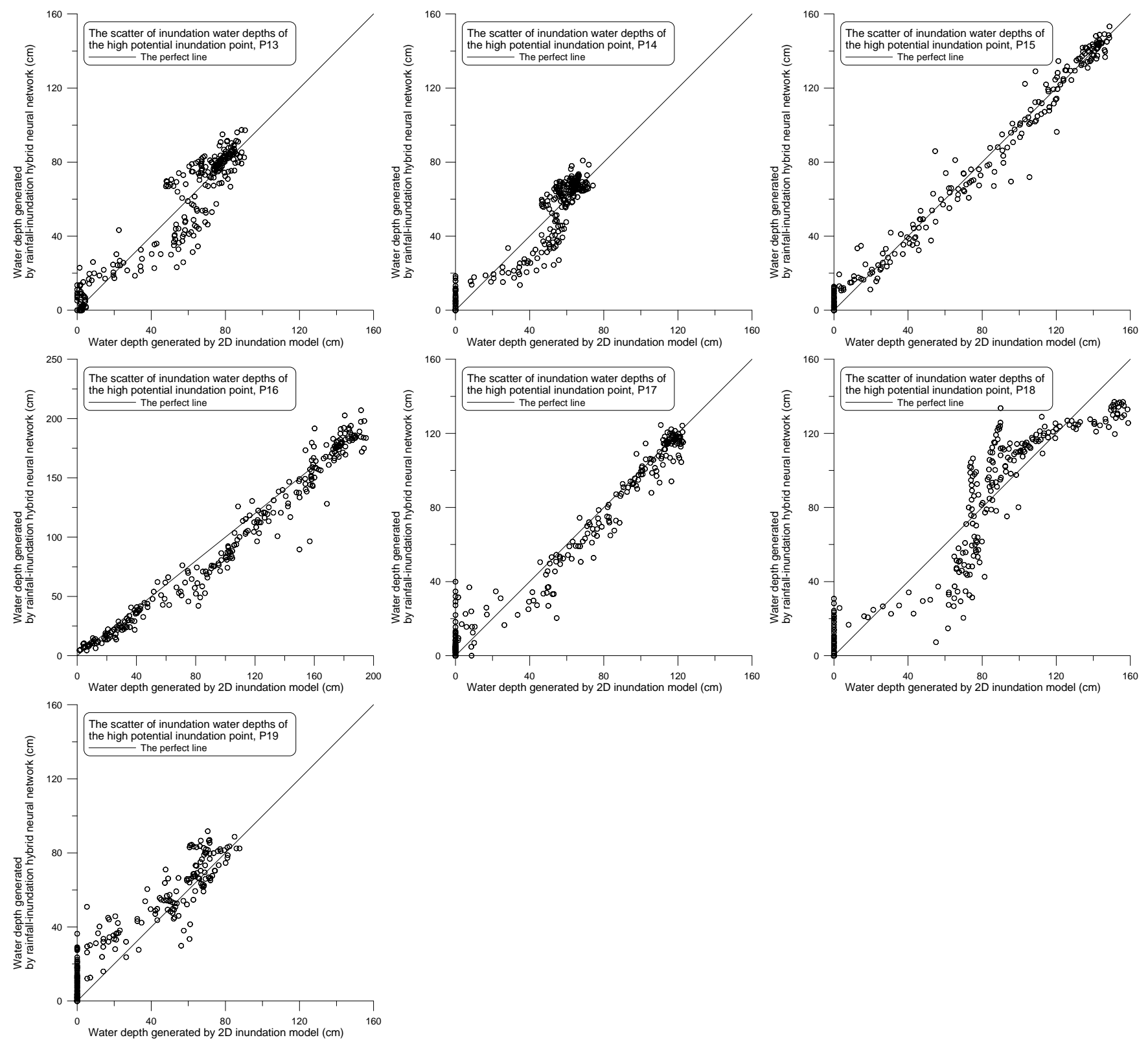

Fig. 9. The scatter plots of the forecast by RiHNN (Model D) and the synthetic inundation by 2-D overland-flow model for the P13 $\sim$ P19 representative inundation locations.

the capability of RiHNNs has been examined through four types of real/synthetic rainfall events, and the performance of rainfall-inundation forecasting via RiHNNs has been evaluated by five criteria. These evaluations reveal that RiHNNs not only forecast inundation depths more accurately for the event with design hyetograph pattern, but also fit inundationdepth hydrographs with higher rainfall well.
The rainfall-inundation results demonstrate that 1-h-ahead forecasting at the representative inundation locations does help emergency managers set operational responses. For the event study of Typhoon Sepat (2007), the elapsed time of advancing $20 \mathrm{~cm}$-deep inundation contour lines from the representative inundation locations (P16, P18 and P19) to the protected villages are about 2 to $3 \mathrm{~h}$, which is beneficial for real-time flood warning preparations. Further study for the algorithm of rainfall-inundation forecasting may be needed to extend the distributed points to inundation extents. 


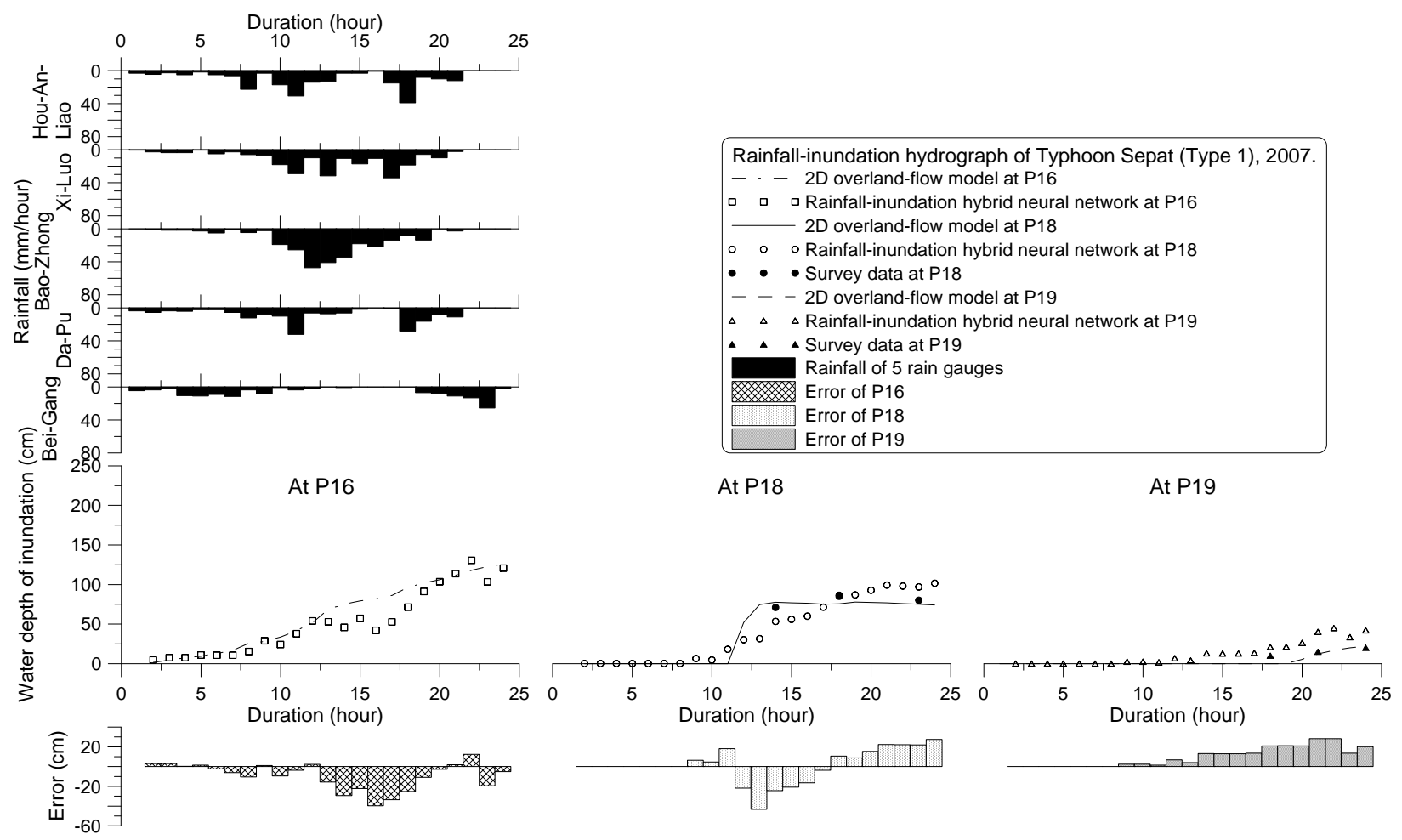

Fig. 10. The rainfall-inundation hydrograph of Typhoon Sepat (Type 1) in 2007.

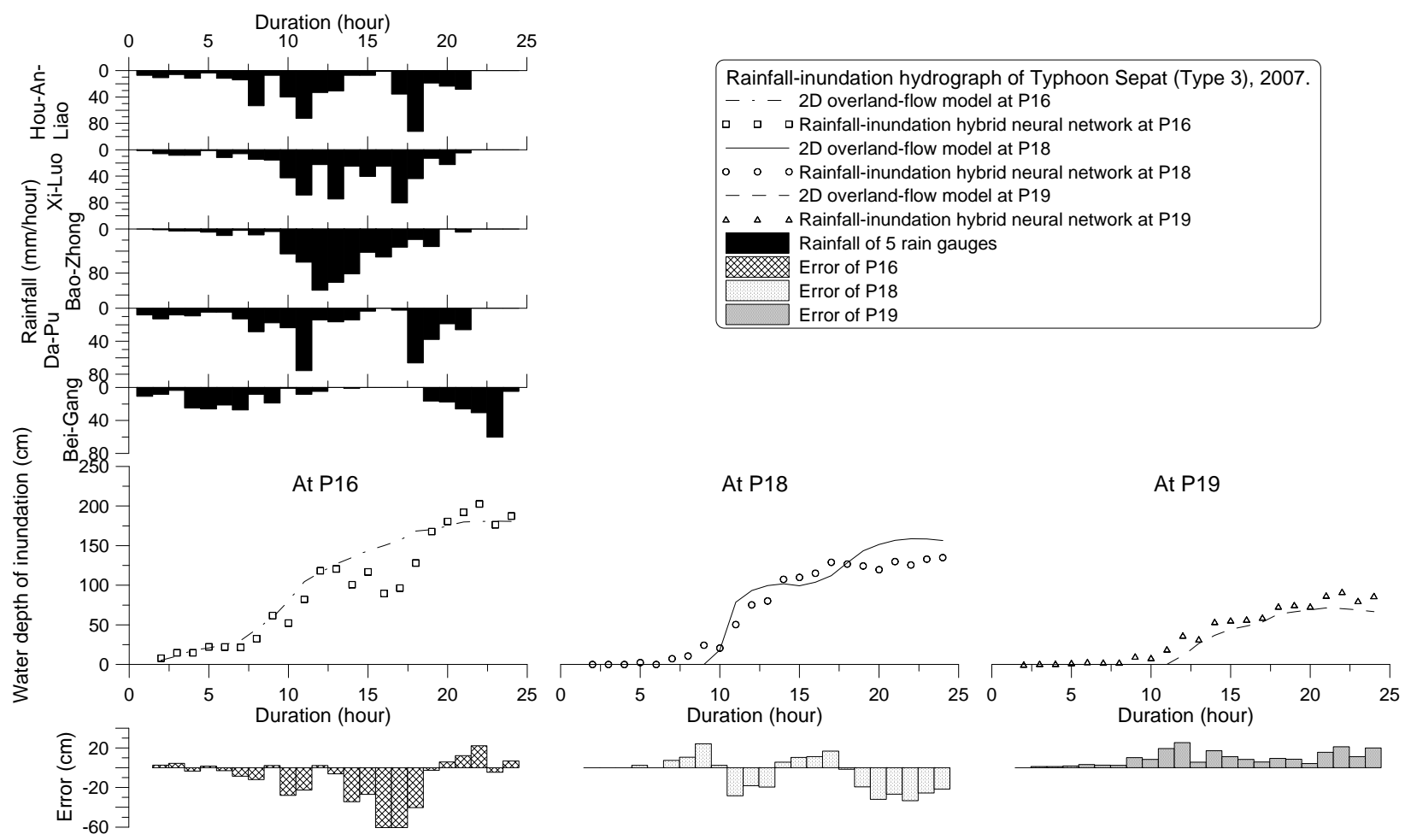

Fig. 11. The rainfall-inundation hydrograph of Typhoon Sepat (Type 3) in 2007. 


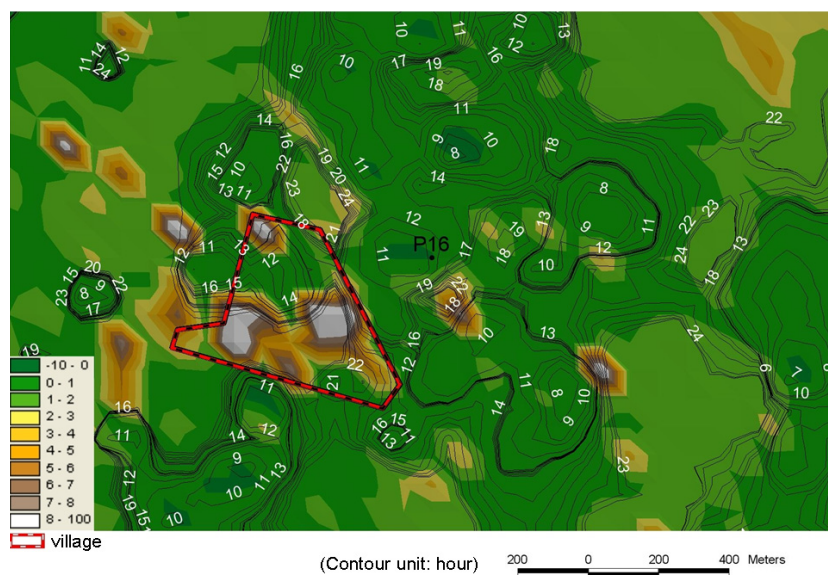

Fig. 12. Topography around P16 with the inundation contours of 20-cm depth advancing with elapsed time (by hour) in Typhoon Sepat.

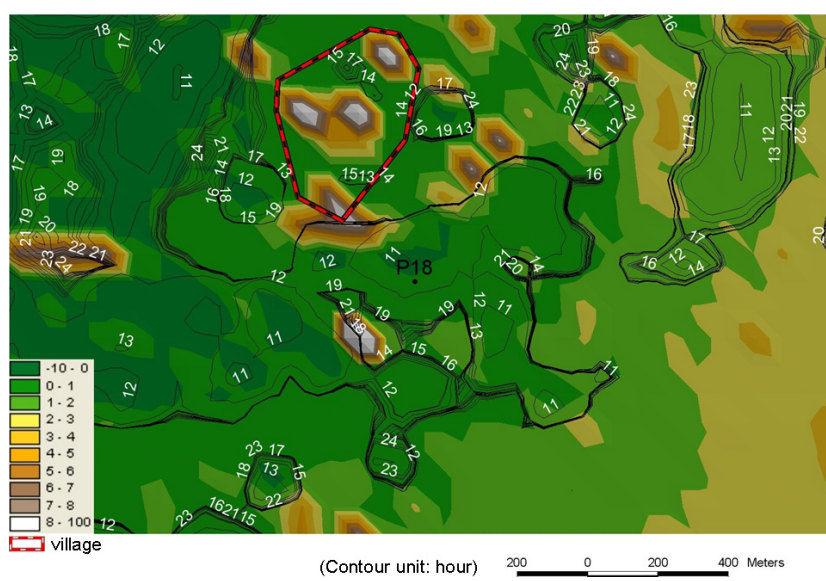

Fig. 13. Topography around P18 with the inundation contours of 20-cm depth advancing with elapsed time (by hour) in Typhoon Sepat.

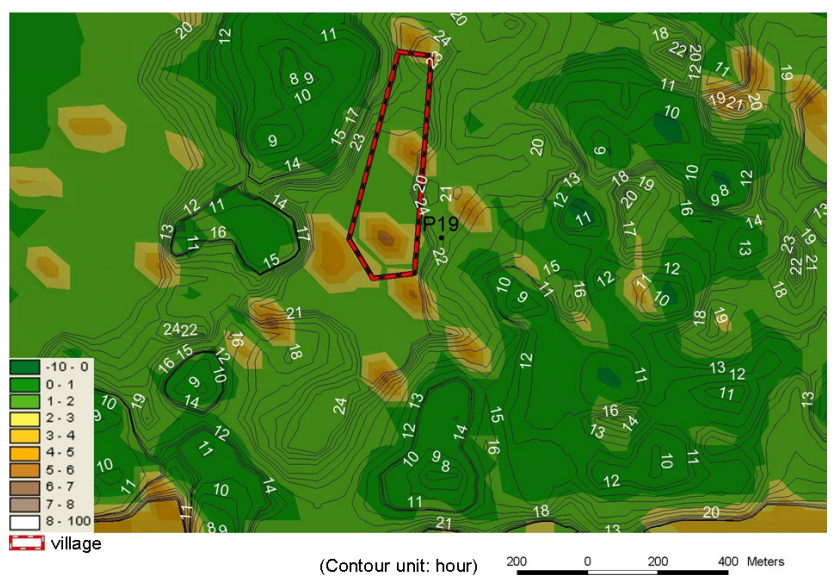

Fig. 14. Topography around P19 with the inundation contours of 20-cm depth advancing with elapsed time (by hour) in Typhoon Sepat.
Acknowledgements. The authors would like to thank the Water Resources Agency, Ministry of Economic Affairs of Taiwan under Grant No. MOEAWRA0950041 and the National Science Council of Taiwan under Grant No. NSC 99-2625-M-002-012-MY3, NSC 99-2625-M-002-002 and NSC 97-2221-E-002-150-MY3 for their partial financial support of this research.

Edited by: R. Lasaponara

Reviewed by: A. Retalis and another anonymous referee

\section{References}

Arnaud, P., Bouvier, C., Cisneros, L., and Dominguez, R.: Influence of rainfall spatial variability on flood prediction, J. Hydrol., 260, 216-30, doi:10.1016/S0022-1694(01)00611-4, 2002.

Bates, P. D. and De Roo, A. P. J.: A simple raster-based model for flood inundation simulation, J. Hydrol., 236, 54-77, doi:10.1016/S0022-1694(00)00278-X, 2000.

Bates, P. D., Marks, K. J., and Horritt, M. S.: Optimal use of highresolution topographic data in flood inundation models, Hydrol Process., 17, 537-557, doi:10.1002/hyp.1113, 2003.

Bodria, L. and Čermák, V.: Prediction of extreme precipitation using a neural network: application to summer flood occurrence in Moravia, Adv. Eng. Softw., 31, 311-321, doi:10.1016/S09659978(99)00063-0, 2000.

Cabinet Office: Disaster Management in Japan, Cabinet office Government of Japan, 48 pp., 2003 (in Japanese).

Chang, T. J., Hsu, M. H., Teng, W. H., and Huang, C. J.: A GIS-assisted distributed watershed model for simulating flooding and inundation, J. Am. Water Resour. As., 36(5), 975-988, doi:10.1111/j.1752-1688.2000.tb05703.x, 2000.

Chau, K. W.: A split-step particle swarm optimization algorithm in river stage forecasting, J. Hydrol., 346, 131-135, doi:10.1016/j.jhydrol.2007.09.004, 2007.

Chen, A. S., Hsu, M. H., Teng, W. H., Huang, C. J., Yeh, S. H., and Lien, W. Y.: Establishing the database of inundation potential in Taiwan, Nat. Hazards, 37, 107-132, doi:10.1007/s11069-0054659-7, 2006.

Chen, S. T. and Yu, P. S.: Pruning of support vector networks on flood forecasting, J. Hydrol., 347, 67-78, doi:10.1016/j.jhydrol.2007.08.029, 2007.

Cheng, K. S., Wang, R. Y., Lin, G. F., Hsu, M. H., Yu, G. H., Yu, P. S., and Lee, K. T.: Handbook for Hydrological Design, Water Resources Agency, China, 2001 (in Chinese).

Chow, V. T., Maidment, D. R., and Mays, L. W. (Eds.): Applied Hydrology, McGraw-Hill Inc., New York, USA, 1988.

Cunge, J. A., Holly Jr., F. M., and Verwey, A. (Eds.): Practical aspects of computational river hydraulics, Pitman Publishing, Boston, USA, 420 pp., 1980.

Dawson, C. W., Abrahartb, R. J., Shamseldinc, A. Y., and Wilby, R. L.: Flood estimation at ungauged sites using artificial neural networks, J. Hydrol., 319, 391-409, doi:10.1016/j.jhydrol.2005.07.032, 2006.

Foody, G. M., Mcculloch, M. B., and Yates, W. B.: The effect of training set size and composition on artificial neural network classification, Int. J. Remote. Sens., 16, 1707-1723, 1995.

Goswami, M. and O'Connor, K. M.: Real-time flow forecasting in the absence of quantitative precipitation forecasts: 
a multi-model approach, J. Hydrol., 334, 125-140, doi:10.1016/j.jhydrol.2006.10.002, 2007.

Guo, W. D., Lai, J. S., and Lin, G. F.: Hybrid flux-splitting finitevolume scheme for the shallow water flow simulations with source terms, J. Mech., 23(4), 399-414, 2007.

Guo, W. D., Lai, J. S., and Lin, G. F.: Finite-volume multi-stage schemes for shallow-water flow simulations, Int. J. Numer. Meth. Fl., 57, 177-204, doi:10.1002/fld.1631, 2008.

Hagan, M. T. and Menhaj, M. B.: Training feedforward techniques with the Marquardt algorithm, IEEE T. Neural. Networ., 5(6), 989-993, 1994.

Haykin, S.: Neural Networks: A Comprehensive Foundation, Prentice-Hall, Upper Saddle River, New Jersey, 1999.

Horritt, M. S. and Bates, P. D.: Evaluation of 1D and 2D numerical models for predicting river flood inundation, J. Hydrol., 268(14), 87-99, doi:10.1016/S0022-1694(02)00121-X, 2002.

Hsieh, L. S., Hsu, M. H., and Li M. H.: An assessment of structural measures for flood-prone lowlands with high population density along the Keelung River in Taiwan, Nat. Hazards, 37, 133-152, doi:10.1007/s11069-005-4660-1, 2006.

Hsu, M. H., Chen, S. H., and Chang, T. J.: Inundation simulation for urban drainage basin with storm sewer system, J. Hydrol., 234, 21-37, doi:10.1016/S0022-1694(00)00237-7, 2000.

Hsu, M. H., Chen, S. H., and Chang, T. J.: Dynamic inundation simulation of storm water interaction between sewer system and overland flows, J. Chin. Inst. Eng., 25(2), 171-177, 2002.

Jolliffe, I. T.: Principal Component Analysis, Springer-Verlag, New York, 1986.

Kerh, T. and Lee, C. S.: Neural networks forecasting of flood discharge at an unmeasured station using river upstream information, Adv. Eng. Softw., 37, 533-543, doi:10.1016/j.advengsoft.2005.11.002, 2006

Kim, G. and Barros, A. P.: Quantitative flood forecasting using multisensory data and neural networks, J. Hydrol., 246, 45-62, doi:10.1016/S0022-1694(01)00353-5, 2001.

Kisi, O. and Kerem Cigizoglu, H.: Comparison of different ANN techniques in river flow prediction, Civ. Eng. Environ. Syst., 24(3), 211-231, doi:10.1080/10286600600888565, 2007.

Lai, J. S., Lin, G. F., and Guo, W. D.: An upstream flux-splitting finite-volume scheme for 2D shallow water equations, Int. J. Numer. Meth. Fl., 48, 1149-1174, doi:10.1002/fld.974, 2005.

Lai, J. S., Guo, W. D., Lin, G. F., and Tan, Y. C.: A well-balanced upstream flux-splitting finite-volume scheme for shallow-water flow simulations with irregular bed topography, Int. J. Numer. Meth. Fl., 62, 927-944, doi:10.1002/fld.2048, 2010.

Lowe, A. S.: The federal emergency management agency's multihazard flood map modernization and the national map, Photogramm. Eng. Rem. S., 69(10), 1133-1135, 2003.

Maier, H. R. and Dandy, G. C.: Neural networks for the prediction and forecasting of water resources variables: a review of modeling issues and application, Environ. Modell. Softw., 15, 101-124, doi:10.1016/S1364-8152(99)00007-9, 2000.

Murphy, D.: Strategy for Flood Risk Management (2003-2008), Environment Agency, UK, 31 pp., 2003.

Nash, J. E. and Sutcliffe, J. V.: River flow forecasting through conceptual models part I - A discussion of principles, J. Hydrol., 10(3), 282-290, doi:10.1016/0022-1694(70)90255-6, 1970.
Pan, T. Y. and Wang, R. Y.: State space neural networks for short term rainfall-runoff forecasting, J. Hydrol., 297, 34-50, doi:10.1016/j.jhydrol.2004.04.010, 2004.

Pan, T. Y., Wang, R. Y., and Lai, J. S.: A deterministic linearized recurrent neural network for recognizing the transition of rainfall-runoff processes, Adv. Water Resour., 30, 1797-1814, doi:10.1016/j.advwatres.2007.02.009, 2007.

Pan, T. Y., Wang, R. Y., Lai, J. S., and Yu, H. L.: Application of Recurrent Neural Networks to Rainfall-runoff Processes, in: Recurrent Neural Networks, edited by: Hu, X. and Balasubramaniam, P., InThech, Croatia, 203-228, 2008.

Romanowicz, R., Beven, K. J., and Tawn, J.: Bayesian calibration of flood inundation models, in: Floodplain Processes, edited by: Anderson, M. and Walling, D., Wiley, Chichester, 333-360, 1996.

Sahoo, G. B. and Ray, C.: Flow forecasting for a Hawaii stream using rating curves and neural networks, J. Hydrol., 317, 63-80, doi:10.1016/j.jhydrol.2005.05.008, 2006.

Sahoo, G. B., Ray, C., and De Carlo, E. H.: Use of neural network to predict flash flood and attendant water qualities of a mountainous stream on Oahu, Hawaii, J. Hydrol., 327, 525-538, doi:10.1016/j.jhydrol.2005.11.059, 2006.

Scales, L. E.: Introduction to Nonlinear Optimization, SpringerVerlag, New York, 243 pp., 1985.

Thirumalaiah, K. and Deo, M. C.: Real-time flood forecasting using neural network, Comput.-Aided Civ. Inf., 13, 101-111, doi:10.1111/0885-9507.00090, 1998.

Toth, E., Brath, A., and Montanari, A.: Comparison of sortterm rainfall prediction models for real-time flood forecasting, J. Hydrol., 239, 132-147, doi:10.1016/S0022-1694(00)00344-9, 2000.

Vongvisessomjai, S., Tingsanchali, T., and Chaiwat, C.: Bangkok flood plain model, in: Proceeding of 21st IAHR Congress, Melbourne, Australia, 433-488, 1985.

Wasantha Lal, A. M.: Performance comparison of overland flow algorithms, J. Hydraul. Eng.-ASCE, 124(4), 342-349, doi:10.1061/(ASCE)0733-9429(1998)124:4(342), 1998.

Wei, Y., Xu, W., Fan, Y., and Tasi, H. T.: Artificial nerual network based predictive method for flood disaster, Comput. Ind. Eng., 42, 383-390, doi:10.1016/S0360-8352(02)00047-5, 2002.

Werner, M., Blazkova, S., and Petr, J.: Spatially distributed observations in constraining inundation modeling uncertainties, Hydrol. Process., 19, 3081-3096, doi:10.1002/hyp.5833, 2005.

Yen, C. L., Hsu, M. H., and Lai, J. S.: Two-dimensional unsteady flow simulation for flood inundation - comparative study on ADE and SES methods, in: Proceeding, in: Symposium on Application of Computer to Civil and Hydraulic Engineering, Taipei, China, 1989 (in Chinese).

Yen, C. L., Loh, C. H., Chen, L. C., Wei, L. Y., Lee, W. C., and Ho, H. Y.: Development and implementation of disaster reduction technology in Taiwan, Nat. Hazards, 37, 3-21, doi:10.1007/s11069-005-4652-1, 2006.

Yu, D. and Lane, S. N.: Urban fluvial flood modelling using a twodimensional diffusion-wave treatment, part 1: mesh resolution effects, Hydrol. Process., 20, 1541-1565, doi:10.1002/hyp.5936, 2006. 